\title{
REFLEXIONES EN TORNO AL RÉGIMEN CONSTITUCIONAL DE SUCESIÓN A LA CORONA ESPAÑOLA
}

\author{
AURORA GUTIÉRREZ NOGUEROLES \\ Profesora Asociada de Derecho Constitucional \\ UNED
}




\section{SUMARIO}

1. INTRODUCCIÓN. 2. La proclamación constitucional de La NueVa MonarQUía. 3. EL RÉGIMEN CONSTITUCIONAL DE SUCESIÓN A LA CORONA. 3.1. La figura del Príncipe heredero. 3.2. El orden de sucesión. 3.2.1. Principios informadores. 3.2.1.1. El principio hereditario. 3.2.1.2. El principio de representación. 3.2.1.3. El principio de primogenitura. 3.2.1.4. El principio de masculinidad preferente. 3.2.1.5. El principio de filiación matrimonial. 3.2.1.6. El principio electivo. 3.2.2. Antecedentes históricos. 3.2.3. Derecho comparado. 3.2.4. Causas de exclusión. 3.3. Las abdicaciones $y$ las renuncias. 4. DUDAS EN TORNO AL ORDEN DE SUCESIÓN A LA CORONA. 4.1. La exhaustividad de la lista sucesoria. 4.2. Los hijos adoptivos en el orden de sucesión. 4.3. La aplicación del principio electivo, ¿Causa de mutación constitucional? 


\title{
REFLEXIONES EN TORNO AL RÉGIMEN CONSTITUCIONAL DE SUCESIÓN A LA CORONA ESPAÑOLA
}

\author{
POR \\ AURORA GUTIÉRREZ NOGUEROLES \\ Profesora Asociada de Derecho Constitucional \\ UNED
}

\section{INTRODUCCIÓN}

Aunque la sucesión a la Corona española se considere, incluso judicialmente ${ }^{1}$, como materia de derecho público constitucional y tenga, como parece obvio, una importancia de primer orden en la configuración de la institución monárquica, la primera impresión que nos produce la lectura de la regulación constitucional sobre ella es, sin duda, la de su notoria parquedad. Ahora bien, aun pudiendo catalogar esta insuficiencia como un defecto de la labor constituyente, según ha sido ya puesto de manifiesto por la doctrina científica ${ }^{2}$, en paralelo a la formulación de tan ajustada crítica se da también el hecho, cierta-

1 Vid. Sentencias del Tribunal Supremo de 27 de julio de 1987, de 28 de abril de 1989 y de 21 de diciembre de 1989.

2 En este sentido, el Profesor LóPEZ VILAS, para quien "la identidad de esta Constitución con las precedentes a nivel de contexto normativo no es plenan. Cfr. LÓPEZ VILAS, R., "La sucesión en la Corona (Comentarios al art. 57 de la Constitúción)", en VV.AA., La Corona y la Monarquía parlamentaria en la Constitución de 1978 (dir. P. LUCAS Verdú), Sección de Publicaciones de la Facultad de Derecho, Universidad Complutense, Madrid, 1983, pág. 134. 
mente paradójico, de que esa parquedad en la regulación constitucional termina apareciendo como un reto al científico del Derecho con interés en el tema, que, de este modo, acaba por reconvertirla en el más adecuado estímulo para emprender una siempre ilusionante tarea investigadora. A nuestro modo de ver, los preceptos constitucionales sobre la materia demandan un nuevo proceso de reflexión sobre ellos, que quizás permita extraer todo el jugo que guardan escondido en su interior y llegar a la conclusión de que, acaso, no llegue a tanto esa insuficiencia reguladora que, a primera vista, se detecta. Participar, en la medida de nuestras posibilidades, en esa nueva reflexión va a constituir, por tanto, la primordial finalidad del trabajo que ahora se inicia.

Para dar principio a nuestra tarea, debemos comenzar señalando que una de las diferencias básicas entre la Jefatura de Estado monárquica y la republicana estriba, como se sabe, en la forma de acceder a su titularidad ${ }^{3}$. En la Monarquía, en efecto, se sustituye el procedimiento de elección o designación típico de la República por un criterio puramente accidental, como es el de la filiación natural, criterio cuya aplicación eleva a la categoría de privilegio el derecho de acceder a tan importante magistratura. Al contrario de lo que ocurre en la República, no puede aspirar a la Jefatura del Estado cualquier ciudadano, sino exclusivamente aquél en quien concurran las condiciones naturales y meramente accidentales (por lo general, la de ser hijo del monarca) que impongan las correspondientes normas constitucionales o legales.

La selección de la persona destinada a ser rey, según afirma $A$. DE LA HERA ${ }^{4}$, debe basarse en dos elementos: la determinación de cuál ha de ser la familia dinástica y el establecimiento de las normas de transmisión hereditaria del título real dentro de dicha familia. Respecto del primero de dichos elementos, cabe afirmar, con J. CREMADES, que es el constituyente quien, por acuerdo o arbitrio, decide «sus-

3 En este sentido, J. DE Esteban y P. GonzÁlez-TREVIJANo, para quienes lo que diferencia a monarquías y repúblicas ues la institucionalización hereditaria del modo de acceso a la titularidad del órgano. Esto es: frente al sistema electivo de las Repúblicas, las Monarquias se basan en una solución biológica o hereditaria". Cfr. De Esteban, J. y GonzÁlez-TreviJano, P. J., Curso de Derecho Constitucional Español, t. III, Servicio de Publicaciones de la Facultad de Derecho, Universidad Complutense, Madrid, 1994, pág. 49.

4 Vid. De la HeRA, A., "Don Juan Carlos I de Borbón, legítimo heredero de la dinastía histórica", en VV.AA., Estudios sobre la Monarquía (coords. A. TORRES DEL Moral y Y. Gómez), Universidad Nacional de Educación a Distancia, Madrid, 1995, pág. 124. 
traer a un grupo de personas con vínculos de sangre, a toda una familia, del posible y legítimo juego político e institucional cotidiano para consagrarla a la más alta de las magistraturas del Estado para que [...] simbolice la unidad y permanencia del Estado y arbitre y modere el funcionamiento mismo de las instituciones" ${ }^{5}$. En cuanto al segundo elemento, son también las normas ad hoc incluidas en los textos constitucionales o legales las que, por regla general, establecen los criterios para determinar, dentro siempre del ámbito de la familia previamente seleccionada, quiénes y en qué orden pueden aspirar, de modo privilegiado, a ocupar la Jefatura del Estado en una Monarquía parlamentaria.

En nuestro país, esta doble tarea viene a realizarla el artículo 57. de la Constitución de 1978, que es el segundo de los diez artículos que, dentro del Título Il y bajo la rúbrica "De la Corona", dedica nuestra norma suprema a la regulación del régimen jurídico de la Jefatura del Estado, como órgano constitucional. En los cinco apartados del mencionado artículo se aglutina, en efecto, todo un conjunto de normas jurídicas destinadas, según los mandatos contenidos en cada una de ellas, a la proclamación de la nueva Monarquía constitucional, a establecer determinados extremos de su régimen jurídico (el orden de sucesión a la Corona y causas de exclusión del mismo, así como el estatuto jurídico del Príncipe heredero) y, en tercer y último lugar, a efectuar una remisión a la ley orgánica para la regulación de abdicaciones y renuncias y para resolver las dudas de hecho o de derecho que surjan respecto del orden sucesorio previsto en la Constitución. Veamos ahora algunos de los principales aspectos de este conjunto normativo.

\section{LA PROCLAMACIÓN CONSTITUCIONAL DE LA NUEVA MONARQUÍA}

La referencia explícita a S. M. D. Juan Carlos I de Borbón, hecha por el artículo 57.1 CE en su inicio, supone la proclamación de una nueva Monarquía y de su primer titular en ejercicio, al que viene indudablemente a otorgar la legitimidad democrática, de la que hasta ese momento carecía. Por más que la norma citada tenga su base en un

5 Cremades García, J., "Efectos del principio hereditario en las funciones moderadoras, arbitral y simbólica del Rey", en VV.AA., Monarquía y Constitución (dir. A. TORRes del MORAL), vol. I, Edit. Colex, Madrid, 2001, pág. 199. 
hecho cierto y consumado - la existencia de la Monarquía juancarlista desde el 22 de noviembre de 1975-, hecho al que, de alguna manera, debe brindar su reconocimiento por mor de las circunstancias políticas que confluyeron en la coyuntura histórica de la transición, no por ello deja de tener el mandato constitucional del 57.1 el impulso creativo suficiente para dar lugar a una nueva Monarquía, "restaurada", si se quiere, por la coincidencia fáctica de que su primer titular pertenezca a la misma dinastía borbónica reinante en España hasta 1931, pero que, desde el punto de vista jurídico, único que ahora interesa, se instaura ex novo, como algo absolutamente original, por virtud de dicho mandato ${ }^{6}$.

En otras palabras, aunque la Monarquía sea una institución de honda raigambre en la historia política española y, obviamente, preexista a la Constitución de 1978, ésta no se limita a acoger la vieja institución para ponerla al día, dotándola de nuevas reglas de juego, sino que, dando un significativo salto cualitativo, establece - con toda la fuerza del poder constituyente- una nueva y original Monarquía, la parlamentaria, que carece de cualquier elemento jurídico de enlace no sólo con la Monarquía borbónica finiquitada en 1931, sino incluso con la inmediatamente anterior a la promulgación del vigente texto constitucional. Sólo a título de excepción y por tratarse de un elemento accidental, que en nada afecta a la esencia de la nueva institución, dan acogida los artículos 56.2 y 57.2 CE a los títulos nobiliarios que pueden ser utilizados por el Rey y a los "vinculados tradicionalmente al sucesor de la Corona de España" para determinar que éste los siga ostentando, pudiendo verse, incluso, en esta determinación una significativa prueba del carácter novedoso de la Monarquía, pues parece claro que, de no tener dicho carácter, el mandato del $\mathbf{5 7 . 2}$ sería superfluo.

6 Seguimos en este punto la opinión de TORRES DEL MORAL, para quien los derechos dinásticos de la Casa de Borbón no pueden hacerse valer jurídicamente frente al poder constituyente, como ocurriria si se diera una "restauración" y es por ello que lo que se produce, por imperativo constitucional, es una «instauración» monárquica en la persona de D. Juan Carlos I, al que el artículo 57.1 CE declara "legítimo heredero de la dinastía histórica", a la vista de que lo prudente y lo único politicamente posible, en el momento constituyente, era recurrir a dicha dinastía. Pero nótese -observa el citado autor- la enorme distancia entre la fórmula constitucional que se acaba de transcribir y la expresión "heredero de la dinastía histórica legítima", que habría sido la utilizada en caso de que el constituyente se hubiera inclinado por una restauración. Vid. TORRES DEL MORAL, A., "La Monarquía parlamentaria como forma política del Estado español», en VV.AA., La Corona y la Monarquía..., op. cit., págs. 51-53. 
De este modo y jurídicamente hablando, el Rey D. Juan Carlos I no es el sucesor, a título de Rey, del General Franco, según estaba previsto en las leyes fundamentales del Estado franquista ${ }^{7}$, ni es tampoco el heredero de la dinastía histórica y ni siquiera es, en fin, la suprema magistratura prevista en la Ley para la Reforma Política, cuya aprobación, mediante el referendo de 15 de diciembre de 1976, podría haberle proporcionado, en opinión doctrinal8, una "embrionaria" legitimación democrática. Se trata, por el contrario, del primer titular de una nueva Monarquía, que nace ope Constitutionis y que, precisamente por esta forma de nacimiento, resulta democráticamente legitimada.

En contra del parecer de un importante sector doctrinal ${ }^{9}$, no obsta a la afirmación que acabamos de hacer la alusión que el citado ar-

7 La sucesión del General Franco había sido regulada, fundamentalmente, en la Ley de Sucesión a la Jefatura del Estado, de 26 de julio de 1947, cuyo artículo $1^{2}$ se refería a España como "Estado católico, social y representativo, que, de acuerdo con su tradición, se declara constituido en Reino". En su artículo 9 se establecían los requisitos a reunir por el candidato a la sucesión, mientras que los artículos 6 y 8 fijaban el procedimiento de designación. De conformidad con estos preceptos y una vez cumplido el requisito de edad por D. Juan Carlos de Borbón, el General Franco propuso a éste como su sucesor a título de rey, mediante un proyecto de ley presentado a las Cortes el 22 de julio de 1969, que resultó aprobado por una mayoría de 491 votos a favor (de un total de 519 Procuradores asistentes). En la tarde del día siguiente, hubo una nueva sesión del Pleno de las Cortes para tomar al sucesor el preceptivo juramento de fidelidad a las Leyes fundamentales y a los Principios del Movimiento Nacional, como estaba previsto en el artículo 8:IV de la citada Ley. Datos extraídos de FerRando BadiA, J., El régimen de Franco, Edit. Tecnos, Madrid, 1984, págs. 285-286.

8 En este sentido, Ferrando Badía, J., El régimen..., op. cit., pág. 283. Vid. también TOMÁs VILLARROYA, J., "La legitimidad dinástica y la legitimidad democrática", en su Comentario al artículo 57, dentro de la obra colectiva Comentarios a la Constitución española de 1978 (dir. O. ALZAGA), tomo V, Cortes Generales y Editoriales de Derecho Reunidas, Madrid, 1997, pág. 90.

9 Según A. PÉREZ de ARMIŃÁN, la Corona es uUna institución histórica recogida y regulada por la Constitución nuevamente, pero no creada por ella, sin perjuicio de que su virtualidad juridica derive del expreso reconocimiento constitucional", fundamentando esta opinión en la alusión constitucional a la "dinastía histórica". Cfr. Pérez de ARMiñán y de LA Serna, A., "La dinastía histórica y el orden de sucesión», en Comentario al artículo 57.1, dentro de Comentarios..., op. cit., pág. 93. En la misma línea, argumenta HeRRERO dE MiÑón que "la Monarquía preexistía a la Constitución y se insertó en ella, pero no derivó nunca de ella. Así lo revelan las referencias a la legitimidad histórica y a la titulación tradicional'». Cfr. HerRero DE MiÑón, M., "La posición constitucional de la Corona", en VV.AA., Estudios sobre la Constitución española. Homenaje al Profesor Eduardo Garcia de Enterría, Madrid, 1991, vol. III, pág. 1925. Vid. también SÁNCHEZ AGESTA, L., Sistema político de la Cons- 
tículo 57.1 CE realiza a la condición de "legítimo heredero de la dinastía histórica" ${ }^{10}$. Se trata, a nuestro modo de ver, de una simple aposición, es decir, una construcción gramatical de finalidad especificativa, que en este caso no tiene otro alcance que el de subrayar el hecho histórico, meramente accidental, de que en el titular de la Corona, el Rey D. Juan Carlos I, se da un plus de legitimidad histórica, que se añade, de hecho, a la democrática, pero que, desde la perspectiva jurídicoconstitucional, no tiene mayor relevancia. En otras palabras, D. Juan Carlos no habría dejado de ser menos Rey ni la nueva Monarquía habría sufrido deterioro alguno si el Conde de Barcelona no hubiera querido efectuar la cesión de sus derechos históricos al trono de España ${ }^{11}$. Tal cesión, a nuestro entender, sólo pudo producir efectos en la esfera privada o, si se quiere, en el ámbito interno de la dinastía histórica, pero no tuvo trascendencia alguna en el orden constitucional12, cuya normación en ningún momento vino determinada por la condición de "legítimo heredero de la dinastía histórica" del Rey D. Juan

titución española de 1978, Edit. Edersa, Madrid, 1984, pág. 56; y DE LA HERA, «Don Juan Carlos...», op. cit., pág. 126.

10 Esta expresión, que no figuraba en el proyecto constitucional aprobado por el Congreso, se introdujo en su texto al resultar aprobada una enmienda (la número 241) presentada, durante la tramitación en la Cámara Alta, por el Senador D. Joaquín Satrústegui. En opinión de BAR CENDón, "la introducción de esta frase resulta un tanto inoportuna, en la medida en que constata de manera excesiva [...] la limitación que el reconocimiento fáctico y formal de la Monarquía [...] imponia al proceso constituyente". Cfr. BAR CENDÓN, A., "La Monarquía parlamentaria como forma política del Estado español según la Constitución de 1978», en VV.AA., Estudios sobre la Constitución Española de 1978 (dir., M. Ramírez), Edit. Pórtico, Zaragoza, 1979, pág. 145.

11 El Conde de Barcelona, D. Juan de Borbón, hizo la cesión formal de sus derechos históricos en favor de su hijo el Rey en una sencilla ceremonia, celebrada en el Palacio de la Zarzuela el día 14 de mayo de 1977: "Creo llegado el momento -dijo en dicho acto el Conde de Barcelona - de entregarle el legado histórico que heredé $y$, en consecuencia, ofrezco a mi Patria la renuncia de los derechos históricos de la Monarquía española, sus títulos, privilegios y la Jefatura de la Familia y la Casa Real de España, que recibí de mi padre el Rey D. Alfonso XIII".

12 En contra, TOMÁs VILLARROYA, para quien esta ceremonia tiene "una significación especial, que supera los límites de un acontecimiento familiar: la cesión por parte de $D$. Juan de Borbón y la aceptación por su hijo de unos derechos que aquél recibió de $D$. Alfonso XIII reanuda la continuidad sucesoria; $y$, de alguna manera, la instauración de una nueva Monarquía en una dinastía que iniciaba $D$. Juan Carlos se convertía en una restauración". Cfr. TOMÁs VILLARROYA, "La legitimidad...", op. cit., pág. 87. De esta misma opinión parece ser SÁNCHEZ AGESTA, que pone un significativo título ( De la Monarquía instaurada a la Monarquía restaurada") a uno de los apartados de su obra citada en la nota núm. 6 (vid. Sistema..., op. cit., pág. 29). 
Carlos, según puede deducirse de la lectura del debate constituyente sobre esta materia ${ }^{13}$.

\section{EL RÉGIMEN CONSTITUCIONAL DE SUCESIÓN A LA CORONA}

A una nueva Monarquía corresponde un nuevo régimen jurídico y a establecerlo se dedica, con toda lógica, el constituyente español de 1978, empleando en ello - como ya ha quedado expuesto- los diez artículos (del 56 al 65) que integran el Título II del texto constitucional. Esta normativa no sigue una línea uniforme, ya que, mientrás determinadas materias las regula con bastante detalle e, incluso, pudiéramos decir que de una forma exhaustiva, otras, en cambio, son tan sólo dibujadas en sus líneas maestras, remitiendo o no, según los casos, a una normación de menor rango para concretar los detalles. La sucesión a la Corona se encuentra dentro de este segundo caso: el constituyente se limita a trazar de modo esquemático su régimen jurídico en el artículo 57 y, siendo quizás consciente de la parquedad de su regulación, hace terminar dicho artículo con una remisión a la ley orgánica para la regulación de las abdicaciones y renuncias y para la resolución de "cualquier duda de hecho o de derecho que ocurra en el orden de sucesión a la Corona". Analizando el contenido normativo de los cinco apartados en que se desglosa el referido artículo, podemos hallar los tres temas centrales del régimen constitucional sucesorio, que son los siguientes: la figura del Príncipe heredero; el orden de sucesión a la Corona; y las abdicaciones regias y las renuncias al derecho de acceder al trono.

\subsection{La figura del Príncipe heredero}

A pesar de -en expresión de J. DE ESTEBAN- "la importancia constitucional que posee la figura de aquél que está llamado a convertirse en Monarca» ${ }^{14}$, el constituyente no ha sido, ciertamente, muy

13 Un detallado análisis sobre este debate puede encontrarse en CAVERO, I., "La Monarquía en el debate constituyente", en VV.AA., Monarquía y..., op. cit., págs. 139 y ss.

14 De Esteban, J., Curso de Derecho Constitucional Español, vol. III, Madrid, 1994, pág. 63. 
generoso a la hora de diseñar el estatuto jurídico del Príncipe heredero ${ }^{15}$. De la lectura del artículo 57.2 CE tan sólo cabe deducir que esta condición se adquiere, bien por causa del nacimiento, bien por la producción de algún otro hecho (por ejemplo, la muerte o la renuncia de un predecesor en el orden de sucesión a la Corona) que origine su llamamiento a suceder, ostentando desde ese momento, según ya se ha comentado, "la dignidad de Príncipe de Asturias y los demás títulos vinculados tradicionalmente al sucesor de la Corona de España». A esta escueta mención del artículo 57.2 CE tan sólo cabe añadir, para completar el diseño constitucional de la figura del Príncipe heredero, las previsiones de otros dos preceptos de nuestra norma suprema: el artículo 59.2, que le habilita, si es mayor de edad, para ejercer, de modo inmediato, la regencia en caso de inhabilitación del Rey para el ejercicio de su autoridad, debidamente reconocida por las Cortes Generales; y el artículo 61.2, que obliga a prestar, también ante las Cortes y tras haber alcanzado la mayoría de edad, el mismo juramento que debe hacer el Rey ${ }^{16}$, así como el de fidelidad a éste. Eventualmente, también pueden afectarle, al igual que al resto de las personas incluidas en el orden de sucesión a la Corona, la previsión del artículo 57.4 respecto de la pérdida de los derechos sucesorios y la muy escueta alusión que hace el artículo 57.5 al tema de la renuncia a tales derechos.

Y esto es todo lo que la Constitución de 1978 estatuye sobre el sucesor del Rey, sin que disponga tampoco un desarrollo normativo de la materia (salvo la remisión a ley orgánica del artículo 57.5, que, por tener un objeto más genérico, sólo de forma tangencial podría afectarle). Parece evidente, pues, la conveniencia de que este incipiente estatuto jurídico del Príncipe Heredero sea ampliado por vía de legislación ordinaria, conveniencia que, a falta del pronunciamiento que sin

15 El estatuto jurídico del Príncipe heredero ha sido muy detalladamente estudiado por el Profesor TORRES DEL MORAL, aunque reconozca abiertamente esa parquedad de la regulación constitucional: "Cuando nos asomamos a la Constitución en busca de criterios para el estudio del estatuto jurídico de los miembros de la Familia regia y, en particular, del Príncipe de Asturias, el panorama no puede ser más desolador, al menos aparentemente. Pues ¿qué hay en nuestro texto fundamental acerca de dichas personas? Nada. Lo diré menos tajantemente: casi nada". Cfr. Torres del Moral, A., El Príncipe de Asturias (Su estatuto jurídico), Publicaciones del Congreso de los Diputados, Madrid, 1997, págs. 27-28.

16 Según el artículo 61.1 CE, este juramento es el «de desempeñar fielmente sus funciones, guardar y hacer guardar la Constitución y las leyes y respetar los derechos de los ciudadanos y de las Comunidades Autónomas». 
duda debió hacer el texto constitucional, viene siendo puesta de manifiesto por la doctrina científica ${ }^{17}$.

\subsection{El orden de sucesión}

La determinación del orden de preferencia en que deben ser llamadas a ejercer la magistratura regia las personas en las que concurren los requisitos constitucional o legalmente exigidos para ello constituye, sin duda, uno de los elementos de mayor relevancia dentro del régimen de sucesión a la Corona.

En nuestra norma suprema esta función la cumple el artículo 57.1, que comienza por calificar al orden sucesorio como "regular", lo que equivale a decir que no hay exclusión de la mujer en la sucesión. Este término se utiliza, en efecto, en relación con los mayorazgos, a los que tradicionalmente se califica como "irregulares" cuando, por decisión del fundador, su sistema sucesorio excluye a las mujeres; se consideran, por el contrario, "regulares" aquéllos en los que tal exclusión no se establece. Así, ya en un conocido dictamen de los obispos españoles, de fecha 7 de octubre de 1789, se decía lo siguiente: "[...] el fundador de un nuevo mayorazgo puede, sin duda alguna, establecer el orden de sucesión de una manera i rregular y por agnación rigurosa, excluyendo para siempre a las hembras, porque los bienes con que funda el mayorazgo son libres y le pertenecen, mas el que hereda un reino o mayorazgo, en que la sucesión es regular y no por agnación rigurosa, no tiene el derecho que tuvo el fundador para alterar una parte sustancial del mismo; podrá renunciar para si personalmente a la posesión del mayorazgo, mas en ningún caso podrá hacer cosa perjudicial a los derechos de sus hijos y descendientes»" ${ }^{18}$.

17 En este sentido, Torres del Moral, El Principe..., op. cit. pág. 32. Hace alusión este mismo autor a que uen 1980 el Gobierno se mostró favorable a la promulgación por ley de un Estatuto de la Familia Real que incorporara ciertas normas dinásticas internas y desarrollara algunos puntos no del todo precisos del Título II de la Constitución, a cuyo efecto el Ministerio de Justicia preparó un proyecto que, sin embargo, no prosperó. Y en 1987 se prefirió elaborar una norma de menor alcance, el Real Decreto 1386/1987, de 6 de noviembre, sobre el Régimen de Títulos, Tratamientos y Honores de la Familia Real y de los Regentes, claramente insuficiente» (op. cit. pág. 28).

18 Este dictamen fue emitido por los obispos españoles a requerimiento del Rey Carlos IV, antes de proceder a la derogación del Auto Acordado de 1713 (vid. infra, pág. 33) y su texto se encuentra recogido en GonzÁLEZ ALONSO, "La his- 
A continuación, el citado artículo 57.1 establece una serie de reglas o criterios, cuya aplicación, conjunta y coordinadamente, viene a traer como resultado la ordenación de los candidatos a la sucesión regia. Ahora bien, tal ordenación no se formaliza en ningún documento escrito ni exige un acto específico de elaboración por el Parlamento o por algún otro órgano constitucional o administrativo. Se trata de una lista hipotética, que puede ir confeccionándose in abstracto, pero que sólo adquiere virtualidad o transcendencia jurídica concreta en un determinado momento histórico, que es el de la abdicación o el del fallecimiento del Rey en ejercicio. De ahí que, durante el periodo de tiempo, normalmente extenso, que transcurre hasta que se produce la situación de vacancia regia, esa hipotética lista pueda verse sometida, con mayor o menor periodicidad, a sucesivas modificaciones originadas por la concurrencia de determinados actos o hechos jurídicos, que implican la inclusión o la exclusión de algún candidato, siendo ocupado su lugar en la citada lista, en este último caso, por el que inmediatamente le sigue.

\subsubsection{Principios informadores}

Las reglas o criterios jurídicos que determinan el orden de sucesión a la Corona no hacen sino expresar el contenido de una serie de principios subyacentes a tal conjunto normativo. A nuestro modo de ver, en el régimen sucesorio de nuestra Carta Magna se hallan los siguientes principios: el hereditario; el de representación; el de primogenitura, en el que debe entenderse implícito el de consanguinidad; el de masculinidad preferente; y el de filiación matrimonial. También debe mencionarse el principio electivo, aun cuando la norma en él basada sólo tenga carácter subsidiario. Estos principios, salvo el de filiación matrimonial, se hallan expresamente recogidos en el artículo 57.1 CE o se deducen implícitamente de él. Obsérvese, no obstante, y ello tendrá las consecuencias jurídicas a las que más adelante nos referiremos, que no hay mención expresa ni referencia implícita al principio de propincuidad.

toria...", op. cit., pág. 27. Para el orden de sucesión a la Corona, su carácter "regularn está recogido de forma detallada en el artículo 180 de la Constitución de Cádiz, cuando se refiere a la sucesión de los descendientes legítimos del Rey, «así varones como hembras"; en las posteriores Constituciones decimonónicas esta detallada expresión será sustituida por la equivalente, pero más sencilla, de «orden regular". 


\subsubsection{El principio hereditario}

Superados ya los tiempos en que las monarquías eran electivas, con los graves inconvenientes ${ }^{19}$ que tal carácter representaba para su estabilidad y consolidación, el principio hereditario aparece hoy como consustancial a la institución monárquica ${ }^{20}$. Su interrelación es tan intensa que podría afirmarse, siguiendo a J. CREMADES, "que la Monarquía tendría importantes dificultades en encontrar su ubicación en el Estado constitucional, si no fuera hereditaria "21. Además, como añade el mismo autor, "la transmisión hereditaria de la dignidad real es expresión del carácter institucional de la Corona»"22.

En virtud de este principio, son llamadas al oficio regio sólo aquellas personas que, conforme a las normas comunes de sucesión hereditaria, reúnen la cualidad de herederos del monarca reinante. $Y$ su manifestación aparece meridianamente clara en nuestro vigente texto constitucional:" "La Corona de España - dice en su inicio el artículo 57.1 CE - es hereditaria en los sucesores de D. Juan Carlos I de Borbón". Al problema de concretar el significado del término "sucesores" tendremos ocasión de referirnos más adelante.

\subsubsection{El principio de representación}

Expresamente mencionado en el artículo 57.1 CE, este principio viene a significar, en el Derecho sucesorio común, que los nietos representan a su padre, en caso de que falleciera antes que el abuelo, en la herencia de éste. Se trata de un principio procedente del Derecho Romano ${ }^{23}$, que se transplanta al campo político, por vez primera, en

19 A título de ejemplo, señala A. JiMÉnEZ-LANDI que "la electividad de la Monarquia [visigótica] produce siete regicidios, incontables víctimas nobles y plebeyas, tres destronamientos sin muerte, uno seguido de la misma; numerosas guerras civiles y varias invasiones extranjeras [...]: la de los bárbaros, la de los bizantinos y la de los moros". Cfr. JIMÉNEZ-LANDI, A., Una ley de sucesión y quince siglos de historia, Edit. Aguilar, Madrid, 1967, pág. 50.

20 En este sentido, Y. GÓMEZ, "Matrimonios regios y sucesión a la Corona en la Constitución Española de 1978», en VV.AA., Estudios..., op. cit., pág. 194.

21 Cremades García, "Efectos del...", op. cit., pág. 199.

22 Cremades García, "Efectos del...", op. cit., pág. 200; vid. también HerReRo dE MiÑón, M., "Comentario al artículo 56. El Rey", en Comentarios a las Leyes Políticas, op. cit., pág. 47.

${ }_{23}$ Ya en el lus civile clásico y, concretamente, en la Ley de las XII Tablas se preceptuaba que, èn caso de sucesión intestada, la herencia se dividiría in capi- 
el Reino de Castilla, al ser incorporado por el Rey Alfonso X El Sabio, como norma de validez general, al Código de las Siete Partidas ${ }^{24}$ (si bien muy probablemente no en su redacción origina| 25 , sino en una revisión posterior a 1269 o a 1275) para regular la sucesión a la Corona, hasta entonces regida por el uso tradicional de que fuera el segundo hijo del Rey quien sucediera a éste, en caso de premoriencia del primogénito. El motivo para este cambio de reglas fue un compromiso de carácter político suscrito, en 1269 , con Francia por Alfonso $X$ al casar a su hijo mayor, el Infante D. Fernando de la Cerda, con Blanca, hija del Rey Luis IX de Francia, compromiso en cuya virtud el hijo que naciese de este matrimonio debería ostentar, en su día, el título de Rey. La introducción del derecho de representación vino, pues, a cubrir el

ta, esto es, en porciones iguales (llamadas "cuotas viriles") entre todos los hijos, pero, si uno de éstos premoría dejando descendientes bajo la potestad del abuelo, la división debería hacerse in stirpes: los nietos reciben la "cuota viril» que hubiera correspondido, de no haber muerto, a su padre. Posteriormente, en el Derecho justinianeo se recoge este mismo precepto en la Novela 118, del año 543: si los descendientes son de igual grado, la herencia se divide por cabezas; si son de grado distinto, por estirpes. Vid. IGLESIAS, J., Derecho Romano (Instituciones de Derecho Privado), Ediciones Ariel, Barcelona, 1965, págs. 637-641.

24 Este Código, también conocido como Libro del Fuero o Fuero de las Leyes, se compone, siguiendo el plan del Digesto, de un Prólogo y de siete partes o "Partidas", divididas en 182 Títulos y en 2802 leyes, reguladoras de materias tan dispares como Derecho eclesiástico, político, administrativo, procesal, civil, mercantil, matrimonial o penal. En la Segunda Partida es, precisamente, donde se desarrolla la constitución política, administrativa y militar del Reino: Emperadores, Reyes, Señores territoriales, Sucesión al Trono, Servicio Militar, Pueblo, Caballería y Ejército. Vid. Pérez-Bustamante, R., Historia del Derecho Español. Las fuentes del Derecho, Edit. Dykinson, Madrid, 1997, pág. 140.

25 El derecho de representación no aparece en el que es, presumiblemente, el texto original de la Ley II, 15, 2 de Las Partidas, a cuyo tenor: "[...] et aun mandaron que si el fijo mayor moriese antes que heredase, si dexare fijo legítimo varón, que aquél lo hubiese; pero si fincare otro fijo varón del rey, que aquél lo herede et non el nieto; et si el fijo mayor non dexare fijo et dexase fija, aquélla lo haya; pero si fincare fija del rey, aquélla lo herede et non la nieta [...]». Esta variante original, que podría datarse probablemente en 1265, figura recogida en el tomo ll de la obra Las Siete Partidas del Rey Don Alfonso el Sabio, cotejadas con varios códices antiguos por la Real Academia de la Historia (Madrid, 1807, pág. 133, nota 2), siendo reproducida en el tomo II (Antología de fuentes del Derecho español) del Manual de Historia del Derecho español de A. García Gallo (Madrid, 1969, pág. 849, f. 1023). En nuestra opinión, el mencionado derecho de representación sólo se incluye en una revisión posterior de la redacción original de la Ley II, 15, 2 por los motivos políticos a que se alude en el texto, pudiendo datarse tal inclusión bien en una fecha posterior a 1269, año en el que se adquiere el compromiso con el Rey Luis IX de Francia, para prever el riesgo del fallecimiento del Infante Don Fernando de la Cerda, bien en 1275, fecha en que dicho fallecimiento se produce. 
riesgo -en potencia o ya concretado en la realidad- de que se produjera el fallecimiento del primogénito y no se pudiera cumplir el referido compromiso político ${ }^{26}$.

En su formulación "política», la que recoge el artículo $57.1 \mathrm{CE}$, el principio de representación viene a significar que el cabeza de una línea posterior no puede ser llamado al desempeño del oficio regio mientras haya miembros de líneas anteriores.

\subsubsection{El principio de primogenitura}

Fundamentado en la idea de unidad e indivisión del reino ${ }^{27} y$ recogido primero en el Espéculo ${ }^{28}$ de Alfonso $X$ el Sabio y después en Las Partidas, este principio determina la preferencia del nacido en fecha anterior respecto de las demás personas llamadas a la sucesión. Su aplicación efectiva tiene una doble dimensión: por un lado, horizontal, ya que establece la preferencia de la línea encabezada por el aspirante de mayor edad respecto de las encabezadas por los demás con el mismo grado de proximidad al titular de la Corona; $y$, por otro lado, vertical, en cuanto que fija la preferencia, dentro de una misma línea, de la persona vinculada al monarca en el grado más próximo. El artículo 57.1 CE asume este principio en su doble dimensión, mediante una mención expresa del principio mismo y dictando el correspondiente mandato en que se concreta: "siendo preferida siempre la

26 En este sentido, González Jiménez, M., "Alfonso $X$, el sueño del imperio", en Revista "La Aventura de la Historia», núm. 45 (julio, 2002), págs. 54-55.

27 En este sentido, TORRES DEL MORAL, A., "La sucesión en la Corona y en los títulos nobiliarios", en VV.AA., Monarquía y..., op. cit., pág. 180; y GonzÁlez ALoNso, B., "La historia de la sucesión en el trono y el artículo 57 de la Constitución de 1978", en Revista de Estudios Políticos (NE), núm. 19 (1981), pág. 11.

28 Con este título de origen germánico y que responde a su pretensión de ser "espejo del Derecho castellano", se conoce la primera obra juridica de carácter general que ordena elaborar, hacia 1255, el Rey Sabio para que llegue a conocimiento de todos sus reinos y de todos los hombres sometidos a su señorio. Se trata, pues, de una compilación del Derecho castellano, que tiene por finalidad la unificación jurídica de Castilla y a la que un sector doctrinal considera como un primer borrador de Las Partidas. En todo caso, su redacción se interrumpió, probablemente por causa de los proyectos imperiales del Rey Alfonso, en 1260. Vid. Pérez-Bustamante, Historia..., op. cit., págs. 137-138; y GonZÁlez-JIMÉNez, "Alfonso X...», op. cit., pág. 55. En cuanto al principio de primogenitura, la Ley II, 16, 1 del Espéculo dispone, en su inicio, que "el fijo mayor del rey es heredero por derecho", justificando a continuación esta preferencia con diversos argumentos. 
línea anterior a las posteriores; en la misma línea, el grado más próximo al más remoto; [...] y en el mismo sexo, la persona de más edad a la de menos".

\subsubsection{El principio de masculinidad preferente}

Frente al principio de masculinidad excluyente ${ }^{29}$, en cuya virtud el acceso al trono queda limitado a los varones del linaje regio (si bien las mujeres pueden transmitir los derechos sucesorios), el de masculinidad preferente no excluye a las mujeres de la sucesión regia, pero sí permite que puedan ser preteridas por varones de su mismo grado de proximidad al Rey. De este modo, la preferencia del varón sobre la mujer sólo podrá aplicarse en los supuestos en que ambos compartan el mismo grado, pues si la mujer forma parte, por ejemplo, de una línea anterior a la del varón conservará su derecho preferente a suceder $^{30}$ (así, en caso de premuerte del primogénito real, su hija -nieta

29 Este principio es de tradicional aplicación en la sucesión a la Corona de Aragón. Fue Jaime I el Conquistador, en su testamento de 1272, quien, después de dividir sus territorios entre sus hijos Pedro (los Reinos de Aragón, Cataluña y Valencia) y Jaime (el Reino de Mallorca, el Condado de Rosellón y el Señorío de Montpellier), dispuso que, si alguno de ellos moría sin hijos varones legítimos, sería sucedido por el otro; y que si ambos morían sin descendencia masculina, el trono correspondería a sus hijos no legítimos (Jaime y Pedro), que serían legitimados para que pudieran ejercer sus derechos. Sólo en caso de que éstos tampoco tuvieran descendencia masculina, pasaría el trono a los hijos varones y legítimos de las hijas del Rey, las cuales en ningún caso podrían reinar, toda vez que, según establecian también las cláusulas testamentarias, si se agotaran las líneas sucesorias sin descendencia masculina, el Reino sería entregado a "aquél que sea el más próximo a nosotros en línea de parentela, siempre que sea varón y legítimo $y$ descienda en línea recta de nuestra estirpe». Así pues, se aplicaba subsidiariamente el llamado "principio de propincuidad". Este sistema sucesorio, que sería objeto de particular aplicación en el Compromiso de Caspe de 1412, rigió en Aragón, incluso, durante la Monarquía de los Austrias, que - como se sabe-siempre respetó las peculiaridades de cada Reino. Su principal diferencia con el sistema vigente en el Reino de Castilla (la incapacidad de las mujeres para reinar) no representó ningún problema para la unidad del Estado, pues ambos sistemas sucesorios, en su respectiva aplicación, siempre coincidieron, curiosamente, en la determinación de los sucesivos herederos de las dos Coronas (es decir, en los cinco reyes de la Casa de Austria). Datos extraídos de JIMÉnEz-LANDI Una ley de sucesión..., op. cit., págs. 93-95; y de TORRES del Moral, "Ĺa sucesión...", op. cit., pág. 181.

30 Este derecho preferente llegó, incluso, a ser reconocido de una forma expresa a la mujer de linaje regio por el artículo 176 de la Constitución de 1812, precepto que, tras declarar la preferencia del varón sobre la mujer en igualdad de 
del Rey y vinculada a éste en segundo grado- tiene derecho preferente a sucederle en la Corona frente al segundo hijo varón del Rey, cuya proximidad es de primer grado).

La preferencia, en igualdad de grado, del varón sobre la mujer para el acceso al trono, típica del régimen de sucesión a la Corona de Castilla ${ }^{31}$, es recogida por el artículo 57.1 de una forma expresa ( [ [...] en el mismo grado, el varón a la mujer [...]"), implicando una evidente excepción a la aplicación del principio de primogenitura, ya que el hijo varón, aunque nazca con posterioridad a la hija, tendrá derecho preferente a la sucesión en el trono. La discriminación que supone para la mujer ha convertido a este precepto constitucional en objeto de fuertes críticas por algún sector, que llega a tacharlo de inconstitucional ${ }^{32}$, si bien la mayoría doctrinal se inclina a admitirlo como excepción, prevista por el constituyente, al principio de igualdad que consagra el artículo 14 de nuestra norma suprema.

\subsubsection{El principio de filiación matrimonial}

Asumiendo la terminología jurídica actual, que, por los sustanciales cambios experimentados en el orden civilístico ( $y$, en particular, en el Derecho de familia, por efecto directo de la aplicación del artículo $39 \mathrm{CE}$ ), ya no utiliza los adjetivos "legítima" e «ilegítima" para calificar los distintos tipos de filiación, denominamos "filiación matrimonial" a la relación existente entre los padres, que se hallan casados entre sí, y los hijos biológicos o naturales nacidos durante la vigencia del matrimonio ${ }^{33}$. La aplicación de este principio al orden de sucesión

grado, dispone literalmente que "las hembras de mejor línea o de mejor grado en la misma línea prefieren a los varones de línea o grado posterior".

31 La preferencia masculina se encuentra ya recogida en el Éspéculo de Alfonso el Sabio, cuya Ley II, 16, 1 dispone que «maguer la fija nasca primero que el fijo e oviese después varón, aquél lo debe heredar [el Reino]», justificándolo en que el hijo "puede por sí mantener el poderio, lo que non puede fazer la fija". Posteriormente, se volvería a recoger en la Ley II, 15, 2 de Las Partídas.

32 En este sentido, Mellado Prado, P., y Gómez Sánchez, Y., "Sobre la posible inconstitucionalidad del apartado 1 del artículo 57 de la Constitución española de 1978", en Revista de Derecho Político núm. 22 (1986), pág. 175.

33 Según la redacción dada por la Ley $11 / 1981$, de 13 de mayo, de modificación del Código Civil, el artículo 108 de este texto legal dispone que "la filiación por naturaleza puede ser matrimonial y no matrimonial. Es matrimonial cuando el padre y la madre están casados entre sí». 
a la Corona obliga a excluir del mismo a los hijos no matrimoniales (del Rey o de cualquiera de los candidatos a sucederle), lo que implica, evidentemente, una excepción al régimen sucesorio común. En este sentido, afirma Y. GÓMEZ que "el concepto de legitimidad referido a los descendientes posee, en la actualidad, una distinta significación en las sociedades civiles democráticas que en el contexto de las familias reales $»^{34}$. Es, precisamente, esta diversidad de significados la que nos obliga a indagar sobre la efectividad del principio de filiación matrimonial en la regulación constitucional sobre el orden de sucesión a la Corona.

Lo primero que al respecto cabe señalar es la ausencia de una mención expresa ${ }^{35}$ a dicho principio en el artículo $57.1 \mathrm{CE}$, si bien algún sector doctrinal ha creído verlo implícito en la regulación general sobre la Corona que hace el Título Il de nuestra Constitución, cuando "contempla y regula, sin excepción, los diversos aspectos [de la Coronal en base al matrimonio del Rey y a la descendencia igualmente matrimonial del Jefe del Estado»36. Por su parte, R. LÓPEZ VILAS lo hace derivar del muy específico Derecho regulador de los títulos de nobleza, en cuanto que consagra el principio de limpieza genealógica o de pureza de sangre ( $e$ en el que tanto insisten los nobiliarios, haciendo remisión a las normas de sucesión en la Corona») ${ }^{37}$, que excluye, sin duda, de la sucesión regia a los hijos antes llamados «ilegítimos".

Aun reconociendo que la admisión de hijos no matrimoniales en el orden sucesorio puede resultar incoherente con el formalismo que envuelve a todo el Título Il y, en particular, al artículo 57.4 CE, no creemos, sin embargo, que la vigencia del principio de filiación matrimonial pueda válidamente fundamentarse en tan genérica base normativa. Se hace necesario, por el contrario, construir una argumentación jurídica más específica y sustantiva, en la que pueda basarse con una mayor solidez la existencia y la aplicación del mencionado principio en nuestro régimen constitucional sucesorio. $Y$ ello porque a tal aplicación parecen oponerse tanto el artículo $14 \mathrm{CE}$, que prohíbe la discriminación por razón de nacimiento, y su complementario el artículo

34 Gómez SÁNCHEZ, "Matrimonios regios...", op. cit., pág. 195.

35 En esto se diferencia tanto de la antigua Ley de Partida como de la mayoría de los textos constitucionales españoles del siglo $X I X$, que se refieren expresamente a la necesaria legitimidad de filiación en los aspirantes al trono.

36 Gómez SÁNCHEZ, "Matrimonios regios...», op. cit., pág. 195, nota núm. 96.

37 LÓPEZ VILAS, «La sucesión...", op. cit., pág. 140. 
39.2 CE ${ }^{38}$, como el artículo 108 CC, a cuyo tenor «la filiación matrimonial y la no matrimonial [...] surten los mismos efectos, conforme a las disposiciones de este Código".

Las prescripciones del citado artículo del Código Civil pueden, sin duda, ser eludidas argumentando que, al estar dirigidas a regular relaciones jurídico-privadas, no tienen por qué aplicars? automáticamente al ámbito de lo público, como aquí sería el caso toda vez que su efectividad se halla en función de su no contradicción con los principios que rigen dicho ámbito. Dicho en otros términos, la sucesión a la Corona no puede identificarse de un modo pleno con la sucesión civil ordinaria y, por tanto, no todas las normas reguladoras de ésta le pueden ser aplicables. De ahí que el mandato del artículo $108 \mathrm{CC}$ podríadecaer respecto de aquella sucesión, si se demostrara su imposibilidad de aplicación en el ámbito público sobre la base de razones o argumentos que transcienden el campo propio del Derecho Civil.

Mayor dificultad reviste salvar la aparente contradicción con el artículo $14 \mathrm{CE}$, toda vez que ello exige justificar convenientemente, mediante sólidos argumentos jurídicos, la excepcionalidad que, frente a la regla general de la igualdad, representa la exclusión de los hijos no matrimoniales del orden sucesorio regio. Ante todo, debemos comenzar por señalar que nos hallamos en un terreno donde la discriminación se acepta con suma naturalidad. Obsérvese, por ejemplo, la preferencia del varón sobre la mujer, a la que antes se hacía alusión. El régimen de acceso al trono - según decíamos en el epígrafe anterior-implica por hipótesis una discriminación, por lo que, si se acepta la Monarquía como forma de la Jefatura del Estado, debe aceptarse también $-y$, por supuesto, con la mayor naturalidad- lo que es una consecuencia inevitable de la misma: la cuota, más o menos grande, de discriminación a la hora de designar un sucesor regio. Cabe entonces preguntarse si resulta constitucionalmente aceptable incluir dentro de dicha cuota la exclusión de los hijos no matrimoniales (del Rey o de cualquier candidato al trono) del orden de sucesión a la Corona. Y la respuesta nos la debe dar, obviamente, la propia norma suprema, por lo que se hace necesario indagar en ella.

A nuestro modo de ver, el único asidero que brinda la Constitución española al jurista que propugne la aplicación al orden sucesorio

38 Según su tenor literal, «los poderes públicos aseguran, asimismo, la protección integral de los hijos, iguales éstos ante la ley con independencia de su filiación [...]". 
regio del principio de filiación matrimonial es el representado por el principio de seguridad jurídica, consagrado - como es sabido-por su artículo 9.3. Sólo sobre la base de este principio puede, en efecto, fundamentarse, a falta de una expresa declaración constitucional, la que creemos implícita necesidad de que los sucesores del Rey se hallen vinculados a él por filiación matrimonial. Y ello es así porque, si existiera la posibilidad de incluir en la sucesión regia a los hijos no matrimoniales, se quebraría, de alguna forma, la obligada certidumbre en el normal funcionamiento de la magistratura suprema del Estado. En efecto, frente a la certeza respecto de la norma y de sus efectos (que es lo que implica esencialmente la seguridad juridica), escasa certidumbre representaría que el acceso a la Jefatura del Estado quedara al albur de que sorpresivamente apareciera algún hijo extramatrimonial del Rey alegando su mejor derecho a sucederle en la Corona por haber nacido antes que el Príncipe de Asturias. Dicho en otros términos, se añadiria una innecesaria dosis de incertidumbre en la aplicación de toda una normativa jurídica de carácter imperativo, lo que, ciertamente, debe hacer pensar que contradice los postulados del principio de seguridad jurídica. De ahí que, en nuestra opinión, la predictibilidad en que consiste, según el Profesor TORRES DEL MORAL ${ }^{39}$, dicho principio no deba circunscribirse solamente a la actividad de los ciudadanos, sino ampliarse al funcionamiento regular de las instituciones en los casos en que, como ocurre en la sucesión regia, su dinámica venga establecida por normas jurídicas de carácter imperativo. Expresión y consecuencia, además, de esa seguridad jurídica referida al funcionamiento institucional es también la regulación del Registro Civil de la Familia Real, hecha por Real Decreto 2917/1981, de 27 de noviembre, registro que, entre otras funciones, viene a prestar la necesaria certeza sobre determinados actos y hechos jurídicos de posible incidencia en el orden de sucesión a la Corona.

En definitiva, pues, la aplicación del principio de filiación matrimonial al orden de sucesión a la Corona viene implícitamente exigida, en nuestra opinión, por el artículo 9.3 CE, al consagrar el principio de seguridad jurídica y en cuanto que este último principio se proyecta no sólo hacia el ámbito de la actividad jurídica de las personas, sino también hacia el del normal funcionamiento de las instituciones. Limitar la integración en el orden sucesorio a los descendientes del Rey por

39 Vid. Torres del Moral, Principios de Derecho Constitucional español, Sección de Publicaciones de la Facultad de Derecho, Universidad Complutense, Madrid, 1998, pág. 161. 
filiación matrimonial no dejaría de ser, de este modo, sino una consecuencia obligada del principio de seguridad jurídica, por derivar implícitamente de su efectividad en el ordenamiento constitucional español.

\subsubsection{El principio electivo}

Este principio se contrapone, lógicamente, al hereditario, por cuanto implica un procedimiento de elección del monarca, cuyo acceso al trono no es, por tanto, motivado por ninguna razón de filiación, parentesco o consanguinidad. Se trata de un principio que hoy se halla prácticamente en desuso, debiendo remontarnos muy atrás en el tiempo para encontrar alguna aplicación práctica del mismo. Así, en el reino visigodo español - nos dice el historiador del Derecho ÁLVAREZ DE MORALES - "la sucesión de la Corona estuvo presidida por el principio del carácter electivo dentro de unas familias nobles determinadas, que originó la inestabilidad política permanente por las luchas de estas familias por el poder y que llevó a los reyes a buscar el principio de la hereditariedad como fórmula para solventar esta crisis, sobre todo mediante la asociación al trono del heredero todavía en vida del Rey, para facilitar este traspaso hereditario; sin embargo, este principio no llegó a imponerse» ${ }^{40}$. Podría, incluso, considerarse que la Monarquía electiva se prolonga durante un período inicial del Reino astur-leonés, que abarcaría los diez primeros reinados, siendo el undécimo de sus reyes, el Rey Ordoño I (850-866), quien consolida el principio hereditario en la sucesión regia ${ }^{41}$. Exceptuando, pues, los dos períodos mencionados (visigótico e inicial del Reino astur-leonés), en los que -como afirma A. DE LA HERA- «jugaron, con mayor o menor precisión, ele-

40 Álvarez de Morales, A., Historia del Derecho y de las Instituciones Españolas, Madrid, 1989, pág. 98. Por su parte, R. GIBERT sostiene que, más que electiva o hereditaria, la Monarquía tuvo un carácter familiar, ya que la elección siempre recaía en familiares del Rey difunto, preferentemente en los primogénitos, $y$, en todo caso, en el pariente más capaz (un hermano, por ejemplo). Cfr. GiberT, R., La sucesión al Trono en la Monarquía española, Les Éditions de la Librairie Enciclopedique, S.P.R.L., Bruxelles, 1969, pág. 466 (cit. en TORRES DEL MORAL, "La sucesión en la Corona...», op. cit., pág. 180). De esta misma opinión es GonZÁLEZ ALoNso, para quien «la transmisión del poder real se verifica, no ya entre los descendientes directos del rey reinante, sino entre los miembros de su familia en sentido lato, de modo que la mera pertenencia a la misma conlleva la expectativa de reinar". Cfr. GonzÁlez Alonso, B., "La historia..., op. cit., pág. 10.

41 En este sentido, JiménEZ-LANDI, Una ley de sucesión.., op. cit., pág. 52. 
mentos tanto hereditarios como electivos", a todo lo largo de la historia de los Reinos hispánicos sólo se ha conocido la Monarquía hereditaria y vitalicia42.

No obstante, a pesar de este tan mínimo arraigo histórico, el apartado $3 \mathrm{del}$ artículo $57 \mathrm{CE}$ acepta el principio electivo, si bien con carácter meramente subsidiario, es decir, cuando de la aplicación del principio hereditario no pueda llegar a seleccionarse un candidato que asuma el oficio regio. Dispone, en efecto, el citado artículo que «extinguidas todas las líneas Ilamadas en Derecho, las Cortes Generales proveerán a la sucesión en la Corona en la forma que más convenga a los intereses de Españan. Se deja, pues, a la discrecionalidad del Parlamento español la elección de un nuevo Rey en el caso de que, por los motivos que fueren, la dinastía fundada por D. Juan Carlos I llegara a extinguirse en un futuro y no fuera capaz, por tanto, de aportar un sucesor regio. Aunque no esté expresamente previsto en el texto constitucional, a este supuesto de extinción física de la dinastía cabría asimilar la incapacidad permanente para reinar del único posible sucesor dinástico.

\subsubsection{Antecedentes históricos}

Dejando al margen la regulación contenida en el Espéculo, que no contempla el principio de representación ni llegó nunca a tener una vigencia general, el actual orden de sucesión a la Corona tiene su primer antecedente histórico en la regulación dada para el reino de Castilla por una ley del célebre Código de las Siete Partidas (en concreto, la Ley II del Título XV de la Segunda Partida), promulgado en 1265 por el Rey Alfonso $X$ el Sabio. Según el texto ${ }^{43}$ literal de esta ley sucesoria, "los hombres sabios y entendidos, catando el procomunal de todos

42 De la Hera, "Don Juan Carlos...", op. cit., pág. 124.

43 Seguimos el texto de la primera edición de Las Partidas, hecha en Sevilla en 1491 por los impresores Maynardo Ungut Alamano y Lançalao Polono, con glosas en castellano de Alonso Díaz de Montalvo. Más adelante, se editaría también en Venecia en 1528 (uno de cuyos originales se conserva en la biblioteca del Colegio de Abogados de Madrid) y en Alcalá de Henares en 1542. Existe, asimismo, una edición considerada oficial por declaración real, que es la glosada por Gregorio López e impresa en Salamanca en 1545. Vid. Pérez-Bustamante, Historia..., op. cit., pág. 141. De la citada en primer lugar existe una edición facsímil realizada por la Editorial Lex Nova (Valladolid, 1989), que incluye una Introducción del Profesor Martínez Díez. 
[...] tuvieron por derecho que el señorío del reino no lo hubiere sino el hijo mayor, después de la muerte de su padre. $Y$ [...] pusieron que el señorío del reino heredasen siempre aquéllos que viniesen por la línea derecha. E por ende establecieron que, si hijo varón no hubiese, la hija mayor heredase el reino. Y aún mandaron que, si el hijo mayor muriese antes que heredase, si dejase hijo o hija que quedase de su mujer legítima, que aquél o aquélla lo hubiese, y no con otro ninguno. Pero si todos éstos falleciesen, debe heredar el trono el más propincuo pariente que hubiese".

Como puede observarse de su lectura, en este texto se contienen ya los principales principios que en la actualidad informan el orden sucesorio, según lo dispuesto en el artículo 57.1 de la Constitución de 1978. En concreto y por el orden en que figuran, vemos que están el principio hereditario, el de primogenitura, el de masculinidad preferente, el de representación ${ }^{44}$, el de filiación legítima y el de propincuidad, siendo este último el único que no se mantiene actualmente. Cabe significar también el predominio de los criterios de racionalidad y de interés público ( "los hombres sabios y entendidos, catando el procomunal de todos...") sobre el de observancia de usos tradicionales, en que se basaba hasta entonces la sucesión a la Corona, si bien la Ley II, 15, 2 mayoritariamente los reconoce y asume, dándoles forma escrita. En este sentido, cabe afirmar, con GONZÁLEZ ALONSO, que dicha Ley "no era una norma por completo respetuosa con los criterios del pasado, ni solicitada por los castellanos o acordada con ellos, sino implantada unilateralmente por los juristas al servicio de la Monarquía, que, en uso de su autoridad legislativa, amalgamó los principios sucesorios tradicionales con la innovación del derecho de representación» ${ }^{45}$. Ello tiene su explicación en el contexto histórico en que se enmarca la promulgación del Código de las Siete Partidas, que obedece a la intención del Rey Sabio de ir sustituyendo paulatinamente la normativa de ámbito local y origen consuetudinario por la de carácter general y procedencia regia ${ }^{46}$. Ahora bien, frente a tal intención, lo cierto es que, en la práctica, el Código no tuvo una inmediata aplicación efectiva por causa de la reacción popular habida contra la legislación

44 Vid. supra, nota núm. 24.

45 GonzÁlez Alonso, "La historia...", op. cit., pág. 15.

46 En este sentido R. PÉrez-Bustamante, para quien "Las Partidas, ante todo, van a representar el intento de sustituir el viejo Derecho de carácter consuetudinario, donde primaban los Fueros como máximo exponente de localismo juridico, por un Derecho general, inspirado claramente en el Derecho Romano justinianeo". Cfr. Pérez-Bustamante, Historia..., op. cit., pág. 138. 
alfonsí, quedando temporalmente como simple obra de consulta, objeto de estudio y de sucesivas revisiones, hasta la declaración de Las Partidas como fuente subsidiaria del Derecho efectuada por el Ordenamiento de Alcalá de $1348^{47}$. De hecho, la sucesión del propio Rey Alfonso $X$ no se rigió por la aludida Ley de Partida, sino por el uso tradicional, vigente en la época, que establecía el acceso al trono, en caso de fallecimiento del primogénito, del segundo hijo varón del Rey. De ahí que fuera el Infante Don Sancho, su hermano menor, y no su nieto Alfonso (al que le hubiera correspondido según la Ley de Partida) quien ocupara el trono a la muerte del Rey Sabio ${ }^{48}$.

En opinión de GONZÁLEZ ALONSO ${ }^{49}$, al que seguimos en este punto, la ley sucesoria de Las Partidas coexiste durante cierto tiempo, concretamente durante los reinados de los cinco reyes de la Casa de Austria, con las normas sucesorias vigentes para la Corona de Aragón ${ }^{50}$, que no permitían que las mujeres reinaran, aunque sí que pudie-

47 Este Ordenamiento, calificado por el Rey Alfonso XI (su coautor junto con las Cortes celebradas en Alcalá de Henares) como verdadero "Libro de las Leyes", tiene una importancia singular por haber sido promulgado con carácter general y por haber fijado, por vez primera, el orden de prelación de las fuentes del Derecho castellano. Según su Título XXVIII, en efecto, se aplicarán, en primer lugar, las leyes contenidas en el propio Ordenamiento (en número de 125); en segundo lugar, los Fueros Municipales y el Fuero Real, en cuanto se probase su uso, y en su defecto el Fuero Juzgo; y, por último, Las Partidas, sobre las que se ordena una revisión. Vid. Pérez-Bustamante, Historia..., op. cit., págs. 142-144.

48 Vid. supra, nota núm.25.

49 Vid. GonzÁlez Alonso, "La historia:...", op. cit., pág. 21. En contra, J. LALIN$\mathrm{DE}$, para quien "el sistema de Las Partidas excluyó sin ninguna declaración oficial al sistema aragonés o al sistema navarro". Cfr. LALINDE GARCíA, J., Iniciación histórica al Derecho español, Barcelona, 1978, pág. 385. De esta misma opinión contraria es García Gallo, que afirma la prevalencia del sistema castellano (vid. Manual..., op. cit., tomo I, pág. 755).

50 En el Reino de Aragón, la sucesión al trono se rigió por las disposiciones al respecto contenidas en los sucesivos testamentos reales, que, a su vez, respetaban los usos y costumbres tradicionales, al igual que hizo el Compromiso de Caspe de 1412, verdadera excepción al método normal de designación del sucesor regio. En esta ciudad aragonesa se reunieron, en efecto, compromisarios de Aragón, Cataluña y Valencia para decidir el problema sucesorio planteado al morir en 1410 el Rey Martín el Humano sin haber instituido heredero de la Corona. Entre los cinco candidatos al trono, los que tenían mayores posibilidades eran Jaime de Urgel, bisnieto de Alfonso IV por línea masculina, y el castellano Fernando de Antequera, nieto de Pedro IV por línea femenina. Los compromisarios, alegando la mayor proximidad de parentesco al Rey fallecido del infante castellano, le nombraron su sucesor. Así pues, esta decisión fue el resultado, según afirma R. GIBERT, de combinar los principios de propincuidad y de filiación legítima. Vid. GIBERT, La 
ran transmitir los derechos de sucesión al trono ${ }^{51}$. Y también coincide en el tiempo (hasta su integración, en 1512, en el propio Reino de Castilla) con las normas sucesorias del Reino de Navarra52, que sí admitían, al igual que las castellanas, la capacidad de la mujer para reinar ${ }^{53}$.

sucesión al Trono..., op. cit., pág. 501 (cit. en TORRES DEL MORAL, "La sucesión en la Corona...n, op. cit., pág. 181). Estos dos principios, junto con los de hereditariedad, primogenitura, representación y masculinidad excluyente, eran los aceptados por los usos y costumbres aragoneses, que siempre rigieron, sin ser siquiera recogidos por escrito, la sucesión a la Corona aragonesa. Vid. GonzÁlez Alonso, "La historia...", op. cit., pág.12.

51 En este sentido, afirma el Profesor GARcía GaLLo que «el Derecho de sucesión del trono que puede considerarse propio de la Corona de Aragón [...] excluye de modo constante $y$ absoluto del trono a las hembras; no simplemente postergándolas a los varones emparentados en grado próximo». Cfr. GARCía GaLLo, A., «El derecho de sucesión del trono en la Corona de Aragón», en Anuario de Historia del Derecho Español núm. 36 (1966), pág. 119. No obstante, tal exclusión dejó de aplicarse, por razones políticas, en dos ocasiones, que fueron los reinados de Doña Petronila y de Doña Juana (hija de los Reyes Católicos), si bien ambas se limitaron a ostentar el título de reina, sin ejercer nunca, en la práctica, el poder real. Esto supone, pues, en opinión del insigne historiador citado, que en la Corona de Aragón "la mujer transmite los derechos que pudieran corresponderle en la sucesión del trono, sin que pueda, en cambio, ejercerlos por sí misma y en nombre propio». Cfr. García Gallo, ibidem, pág. 123. Vid. también supra, nota núm. 28.

52 Ya en el Fuero General de Navarra, en la segunda mitad del siglo XII, se recogieron por escrito, dentro del Título dedicado a la herencia y a la partición hereditaria, los usos que venían rigiendo tradicionalmente la sucesión al trono. Así, la Ley II, 4, 1 establecía lo siguiente: «E fue establido para siempre, por que podiesse durar el regno, que todo Rey que oviere fijos de leyal coniugio dos, o tres, o más, o fijas, pues que el padre moriere, el fijo mayor herede el regno [...]. Et si aquest fijo mayor casado oviere fijos de leyal coniugio, que lo herede su fijo mayor, otrossí, como él fezo. Et si por ventura muere el que regna sen fijos de leyal coniugio, que herede el regno el mayor de los hermanos que fue de leyal coniugion; y la Ley II, 4, 2 completaba la regulación sucesoria, al disponer que " [...] si muere el Rey sin creaturas o sin hermanos o hermanas de pareylla, deven levantar Rey los richos hombres et los ynfanzones cavaylleros et el pueblo de la tierra". Una concreta aplicación de lo dispuesto en el Fuero General tuvo lugar en noviembre de 1419 , con ocasión de los esponsales de Blanca de Navarra con el Infante aragonés Don Juan, cuando las Cortes de Navarra establecieron que el primogénito del matrimonio, ya fuese varón o hembra, heredaría el reino y las posesiones del Infante en Aragón y en Castilla. Vid. GonzÁlez Alonso, "La historia...", op. cit., pág. 17 y nota núm. 18; y JiMÉNEZ-LANDI, Una ley de sucesión..., op. cit., pág. 126.

53 En cambio, no recogían, ni directa ni indirectamente, el derecho de representación de los descendientes del sucesor premuerto, aunque, de hecho, se aplicara en la sucesión de la Reina Leonor, en 1479. Vid. GonzÁlez Alonso, "La historia...", op. cit., pág. 18; y TORRES DEL MORAL, "La sucesión en la Corona...», op. cit., pág. 181. 
Va a ser el primer Rey de la Casa de Borbón, Felipe V, quien -a modo de compensación por su forzada renuncia al trono de Francia 54 y queriendo evitar que las alianzas matrimoniales pudieran en el futuro arrebatar la Corona de España a la dinastía borbónica55- derogará el sistema sucesorio de Las Partidas mediante la Ley Fundamental de Sucesión a la Corona de España ${ }^{56}$, de 18 de marzo de 1713 , y su norma de desarrollo, el Nuevo Reglamento para la Sucesión a la Corona, que, bajo la forma de Auto Acordado57, se incorpora a la legislación general española, tras su promulgación el 10 de mayo de 1713. Dicho Reglamento viene a establecer la exclusión de las mujeres mientras haya varones en alguna línea directa: "A fin de conservar en ella [la sucesión] la agnación rigurosa - dispone el Rey Felipe V-, fuesen preferidos todos mis descendientes varones por la línea recta de varonia a las hembras y sus descendientes, aunque ellas y los suyos fueran de mejor grado y línea». De este modo, a partir de la vigencia de la nueva norma sucesoria sólo se permitirá reinar a las mujeres cuando no exista ningún varón en las líneas agnadas y de ahí que a dicha norma se la conozca también con el nombre de «ley semisálica» 58 .

54 En este sentido, R. DE LA CIERVA, Historia..., op. cit., t. VII, pág. 64.

55 En este sentido, JIMÉNEZ-LANDI, Una ley de sucesión..., op. cit,, pág. 217; según este autor, "para que no se repitiesen las circunstancias que habían dado el trono a Felipe $V$, este mismo Rey, aconsejado por su abuelo [el Rey Luis XIV de Francia], determinó establecer la ley semisálica en nuestro país".

56 Mediante esta Ley, que se incorpora a los Tratados de Utrecht de 1713 por la Real Cédula de 18 de marzo de 1713, se establecía la herencia del trono por línea de varón y la exclusión de los Borbones franceses y de la Casa de Austria, siendo la Casa de Saboya la llamada a recoger la sucesión (por línea descendente de la hija de Felipe II, Catalina Micaela, que había casado, en su día, con el Duque de Saboya) si no hubiera descendencia del Rey Felipe V. Como puede deducirse, el contenido de esta Ley formaba parte de los compromisos recíprocos establecidos entre los diversos Estados firmantes de los Tratados de paz y relativos a la sucesión en las distintas Coronas. Vid., al respecto, JiMéNEz-LANDI, Una ley de sucesión..., op. cit., págs. 194-195.

57 El calificativo de "acordado" tiene su causa en la consideración jurídica del Auto como la formalización de un acuerdo entre el Rey y el Consejo de Estado. Vid. JIMÉNEZ-LANDI, ibidem.

58 Se conoce con el nombre de "ley sálica" (propia de los francos salios) a la que, entre otras disposiciones, excluía a las mujeres de la herencia de tierras, sirviendo esto como fundamento para que diversas monarquías europeas, entre ellas la francesa, excluyeran de la sucesión al trono a las mujeres y sus descendientes. Como en España esta exclusión no llegaba a ser tan absoluta, pues las mujeres podian reinar en defecto de descendientes varones, es por lo que a la ley de 1713 se le denomina "semisálica". Vid., al respecto, DE LA CierVA, Historia..., op. cit., t. VII, pág. 64; y JiMÉnEZ-LANDI, Una ley de sucesión..., op. cit., pág. 217. En este 
Curiosamente, de esta nueva regulación cabe predicar su carácter pactado, ya que se aprueba por el Rey en el marco de unas Cortes convocadas al efecto ${ }^{59}$ el 6 de octubre de 1712 y a instancia del Consejo de Estado, que ve "grandes conveniencias y utilidades" en el nuevo modo de suceder, y con el apoyo, un poco más reticente, del Consejo de Castilla, que actúa -en expresión de S. CORONAS"como guardián celoso de una legalidad tradicional conculcada sin mayor motivo" ${ }^{60}$. Los Procuradores a Cortes, que habian recibido poderes especiales para ello, aprueban, una vez disipados algunos recelos iniciales, la nueva norma sucesoria ${ }^{61}$, otorgándosele, además, de acuerdo con la tradición francesa, el rango de ley fundamental: "[...] y quiero y mando que la sucesión de esta Corona proceda de aquí adelante en la forma expresada, estableciendo ésta por ley fundamental de la sucesión de estos reinos, sus agregados y que a ellos se agregaren, sin embargo de la Ley de Partida y de otras cualesquiera leyes $y$ estatutos, costumbres $y$ estilos y capitulaciones que hubiere en contrario, las quales derogo $y$ anulo en todo lo que fueren contra-

mismo sentido, A. Pérez de ARMIÑÁn señala que "a pesar de la agnación rigurosa [a que alude el texto del Auto Acordado], el orden de sucesión semi-sálico permitía que, a falta de descendientes varones de Felipe $V$, reinara la mujer de mejor línea y grado descendiente de aquél, constituyéndose asi en nueva cabeza de línea y reiniciándose, a partir de ella, la sucesión por vía agnaticia». Cfr. PÉREZ de ARMIŃÁN Y DE LA SERNA, "La dinastía...", op. cit., pág. 104, nota núm. 56.

59 El objeto de convocar a Cortes "a los procuradores de las ciudades, prelados y nobleza de los reinos de Españan fue, primordialmente, la sanción o vali ${ }^{-}$ dación por ley de la renuncia formal a los derechos sucesorios de la Corona de Francia, exigida por las potencias contendientes en la Guerra de Sucesión, particularmente por Inglaterra, que había exigido, además, la sanción por las Cor:tes del acto de renuncia. No obstante, Felipe $V$ quiso aprovechar la ocasión para que las Cortes aprobaran también la modificación del orden sucesorio tradicional establecido en Las Partidas, a cuyo efecto pidió el otorgamiento de poderes especiales a los procuradores. Constituidas las Cortes el día 5 de noviembre de 1712, la renuncia de Felipe $V$, por sí y por sus hijos y demás descendientes, se formalizó en un escrito, que leyó el propio Rey en la sesión de Cortes celebrada cuatro días más tarde, es decir, el 9 de noviembre. A esta ceremonia asistió, incluso, un embajador especial inglés, Lord Robert Lexington, además del embajador francés en España, el Marqués de Bonac. Vid. al respecto, VV.AA., Historia de España. Gran Historia General de los Pueblos Hispanos (dir. L. Pericot García), t. V, Instituto Gallach de Librería y Ediciones, Barcelona, 1975, pág. 35; CoRONAS, S,, "Las leyes fundamentales del Antiguo Régimen (Notas sobre la Constitución histórica española)", en VV.AA., Monarquía y..., op. cit., pág. 43; y JIMÉNEZ-LANDI, Una ley de sucesión, op. cit., pág. 218.

60 CoRonAs, "Las leyes...", op. cit., pág. 43.

61 Vid. De la CierVa, Historia..., op. cit., t. VII, pág. 65. 
rias a esta ley, dexándolas en su fuerza y vigor para lo demás; que asi es mi voluntad"62.

El Auto Acordado de Felipe V se verá, años más tarde, afectado parcialmente por la promulgación de una norma general de Derecho Civil, la Pragmática del Rey Carlos III de 23 de marzo de 1776 (publicada cuatro días más tarde, el 27), que venía a establecer, para cualquier matrimonio a celebrar, la obligación de contar con el consentimiento o con el simple consejo, según los casos, de los padres de los futuros contrayentes. Bajo la apariencia de su generalidad, dicha Pragmática encubre, sin embargo, la oculta intención regia de "castigar" a su hermano, el Infante D. Luis Antonio de Borbón y Farnesio, por su pretensión de contraer matrimonio «desigual» con $D^{a}$. María Teresa Vallabriga y Rozas, mujer de la nobleza aragonesa, pero que no pertenecía, lógicamente, a ninguna familia real63. Aunque formalmente no se trata de una ley, la Pragmática se dicta - por expresa voluntad regia - con fuerza legal ${ }^{64} \mathrm{y}$ así queda incluida, como la Ley IX del Título II del Libro X, en la Novísima Recopilación ${ }^{65}$, que ordena publicar Carlos IV en 1805. Debe reiterarse que no es una ley sobre la sucesión regia, sino que tiene por objeto regular una nueva obligación legal, la de contar con el "consentimiento paterno para la contracción de esponsales y matrimonio por los hijos de familia". Ahora bien, enmarcadas dentro de los preceptos de carácter civil dirigidos a establecer tal obligación y regular los efectos jurídicos derivados de su incumplimiento, aparecen tanto una referencia específi-

62 Coronas, "Las leyes..... op. cit., pág. 43.

63 La boda terminaría celebrándose, ya que el Rey concedió el oportuno permiso apenas dos meses después de la publicación de la Pragmática (concretamente, el 22 de mayo), pero al matrimonio le fueron aplicados todos los efectos de carácter sancionador previstos en la citada norma. No obstante, veintitrés años después y por haber casado una de las hijas del matrimonio con el Primer Ministro Manuel Godoy, el Rey Carlos IV revocó, por Real Decreto de 4 de agosto de 1799, los aludidos efectos punitivos de la Pragmática, rehabilitó al Infante D. Luis Antonio y concedió a los hijos de éste el derecho a usar el apellido Borbón antes que el de Vallabriga con las armas correspondientes, haciéndolos Grandes de España de primera clase y miembros de la Familia Real. Datos extraídos de DE LA CIERVA, R., Don Juan de Borbón: por fin, toda la verdad, Edit. Fénix, Madrid, 1997, págs. 33-36.

64 "He tenido a bien - dice Carlos Ill al final de su disposición normativaexpedir esta mi Carta y Pragmática Sanción con fuerza de ley, que quiero tenga el mismo vigor que si fuera promulgada en Cortes».

65 Su texto puede leerse en la edición facsímil realizada por el Boletín Oficial del Estado en 1993. 
ca a los Infantes, que deben seguir solicitando del Rey la oportuna autorización para casarse ${ }^{66}$ (con la subsiguiente sanción, si no lo hacen, de perder sus derechos sucesorios), como una previsión sobre el tratamiento legal ${ }^{67}$ que debe darse a un caso excepcional e hipotético -el matrimonio desigual de un Infante, aunque sea autorizado por el Rey-, tratamiento que, por sus relevantes efectos de carácter sancionador (entre los que cabe destacar también la pérdida dè los derechos sucesorios a la Corona), debe ser considerado como el auténtico, aunque oculto, objeto de la Pragmática. Así pues, en lo que atañe a la sucesión regia, los descendientes de los matrimonios desiguales, aun cuando éstos sean celebrados con la debida autorización, quedan privados de la sucesión en todas las dignidades y bienes dimanantes de la Corona y excluidos, lógicamente, del orden sucesorio regio; por su parte, a los Infantes contrayentes no se les priva de sus títulos ni de sus bienes, pero sí les afecta lo dispuesto sobre efectos civiles para quienes contraigan matrimonio sin permiso del Rey, por lo que también quedan excluidos de la sucesión regia. Aun cuando estos efectos excluyentes de la Pragmática, incluso después de su revocación en 1799 por el Rey Carlos IV68, fueron aplicados (en

66 En el Apartado XI de la Pragmática dispone el Rey expresamente que "se conserve en los Infantes y Grandes la costumbre y obligación de darme cuenta, y a los Reyes mis sucesores, de los contratos matrimoniales que intenten celebrar ellos o sus hijos e inmediatos sucesores para obtener mi Real aprobación; $y$ si omitiese alguno el cumplimiento de esta necesaria obligación, casándose sin mi Real permiso, asi los contravinientes como su descendencia por este mero hecho quedan inhábiles para gozar los títulos, honores y bienes dimanados de la Corona».

67 En el Apartado XII de la Pragmática, Carlos III dispone lo siguiente: «Pero como puede acaecer algún raro caso de tan graves circunstancias que no permita que deje de contraerse matrimonio, aunque sea con persona desigual, cuando esto suceda en los que están obligados a pedir al Rey permiso, ha de quedar reservado a mi Real persona y a los Reyes mis sucesores el poderlo conceder, pero también en este caso queda subsistente e invariable lo dispuesto en esta Pragmática en cuanto a los efectos civiles $y$, en su virtud, la mujer o el marido que cause la notable desigualdad quedará privado de los títulos, honores y prerrogativas que le conceden las leyes de estos Reinos ni sucederán los descendientes de este matrimonio en las tales dignidades, honores, vínculos o bienes dimanantes de la Corona, los que deben recaer en las personas a quienes, en su defecto, corresponda la sucesión".

68 Vid. supra, nota núm. 62. En ópinión de Y. GómEz, la derogación de la Pragmática se produce en 1812, por su contradicción con lo dispuesto en el artículo 183 de la Constitución de Cádiz, que establece para los miembros de la Familia Real la obligación de contar con la autorización de las Cortes antes de contraer matrimonio. Vid. GómEZ SÁNCHEZ, "Matrimonios regios...", op. cit., pág. 196. 
nuestra opinión, sin ninguna justificación jurídica) a diversos matrimonios desiguales de miembros de la Familia Real a lo largo del siglo $\mathrm{XIX}$, puede afirmarse que, en todo caso, con la publicación del Código Civil de 1889, la norma de Carlos III quedó derogada en su totalidad.

Además de esa parcial incidencia, que acabamos de señalar, en el contenido del Auto Acordado de 1713, la vigencia efectiva de éste sufrirá posteriormente una fuerte sacudida cuando, reunidas las Cortes ${ }^{69}$ en el mes de septiembre de 1789, piden al Rey Carlos IV, pero a iniciativa de éste ${ }^{70}$, la derogación de dicho Auto por - según la afirmación del Conde de Campomanes, Gobernador del Consejo de Castilla y Presidente de la asamblea parlamentaria - "estar hecho contra leyes que existían y estaban juradas" y porque "el reino no había pedido ni tratado una alteración tan notable en la sucesión a la Corona» ${ }^{71}$. El Rey, de quien había partido - como decíamos - la iniciativa derogatoria y tras asumir el contenido del dictamen de los obispos españoles $^{72}$ (que había requerido previamente y que le era favorable), acep-

69 La convocatoria a Cortes en Madrid, hecha el 22 de mayo de 1789, tenía como principal objeto el reconocimiento como sucesor del Príncipe de Asturias, mediante el preceptivo juramento de fidelidad. Sin embargo, se añadió, como coletilla, que también servirían "para tratar, entender, practicar, conferir, otorgar y concluir por Cortes otros negocios, si los propusiesen y pareciese conveniente resolver, acordar y convenir". Y, en efecto, ya en el primer día de su reunión en la iglesia de San Jerónimo el Real (el 23 de septiembre), el Presidente de las Cortes (el Conde de Campomanes) transmitió a los procuradores la voluntad regia de que use trate de una pragmática sobre la ley de sucesiones y otros puntos». Con igual rapidez, la primera propuesta derogatoria, elaborada por el mismo Campomanes, se presentó ante la asamblea parlamentaria siete días más tarde, el 30 de septiembre. Vid. JIMÉNEZ-LANDI, Una ley de sucesión..., op. cit., pág. 219.

70 No están muy claros cuáles fueron los motivos del Rey Carlos IV para instar la derogación. Tal vez pudiera estar influido por las tempranas muertes de tres de sus hijos varones o quizás tuviera la intención de eliminar una disposición del Auto Acordado que prohibía reinar en España a los infantes nacidos fuera de ella (como había sido su propio caso, al haber nacido en Nápoles). Una tercera teoría, que parece la más probable, sitúa la causa en la presión ejercida por la hija predilecta del Rey, la Infanta Carlota Joaquina, quien, por estar casada con el Príncipe heredero portugués, nunca perdió la esperanza de ver a su primogénito ciñendo las dos Coronas peninsulares. Cualquiera que fuere el motivo, las Cortes, por unanimidad, aceptaron la iniciativa regia y presentaron al Rey la correspondiente petición. Vid. DE LA CIERVA, Historia..., op. cit., t. VIII, pág. 18; y JimÉnEZ-LANDI, Una ley de sucesión..., op. cit., págs. 218-219.

71 Vid. Coronas, "Las leyes...", op. cit., pág. 54.

72 Vid. supra, nota núm. 17, en la que puede leerse el principal fundamento jurídico de este dictamen. 
ta la representación ${ }^{73}$ parlamentaria en una Resolución, que es leída ante las Cortes el 31 de octubre: "Ordenaré a los de mi Consejo-rezaba la referida Resolución-expedir la pragmática sanción que en tales casos corresponde y se acostumbra, teniendo presente vuestras súplicas y los dictámenes que sobre ella haya tomadon. Con este último trámite se hubiera completado el procedimiento derogatorio iniciado por el Rey, continuado por la petición parlamentaria y finalizado con la Resolución Real y su correspondiente ratificación por las Cortes, pero, p-obablemente por razones de oportunidad política ${ }^{74}$, la Pragmática 'Iunca llegó a publicarse, por lo que faltó un requisito esencial para la : serogación del Auto Acordado de 1713. Es más, el propio Rey, lejos de ordenar la publicación de la Pragmática, pidió secreto a las Cortes "y así lo ofrecieron todos los caballeros procuradores, deseosos de que no :ólo en la sustancia, sino en el modo, se asegure esta providencia y ley constitucional", quedando dicha publicación "pendiente hasta el tiempo que tuviere por conveniente el Rey según su alta previsión". De este modo, por la falta del último trámite necesario para la eficacia de la norma derogatoria, el Auto Acordado de Felipe $V$ siguió formalmente vigente ${ }^{75}$. Como dice R. DE LA CIERVA, " "la ley semisálica seguia vigente en la conciencia nacional, aunque derogada en la conciencia real» 76 .

Ahora bien, esa vigencia formal del Auto Acordado resultaría temporalmente suspendida de hecho por la Constitución de Bayona de 6 de julio de 1808 (otorgada, como se sabe, por el Rey usurpador francés, José Bonaparte), al establecer en su artículo $2^{\circ}$ la antigua "ley sálica" de los francos, que excluía absolutamente a las mujeres del acceso al trono, no permitiéndoles siquiera transmitir a sus hijos varo-

73 Dentro de los diversos significados que, en el lenguaje jurídico, presenta el término "representación", se halla el que tiene en nuestro Derecho histórico como sinónimo de "petición, queja o demanda" dirigida al monarca, previo el cumplimiento de ciertos requisitos formales. Vid. TORRES DEL MORAL, A., Estado de Derecho y democracia de partidos, Servicio de Publicaciones de la Facultad de Derecho, Universidad Complutense, Madrid, 1991, pág. 342.

74 Parece ser que el Rey no consideraba coherente su autoría en la derogación de este sistema sucesorio agnaticio de origen francés con la posibilidad cierta que tenía de llegar, mediante ese mismo sistema, al trono de Francia, si se daban las circunstancias adecuadas.

75 De ahí que figurara incluida, como la Ley $V$ del Título $X$ del Libro III, en la Novísima Recopilación de 1805, inclusión que, según GonzÁLEZ Alonso, "produjo cierta perplejidad a los juristas que no ignoraban lo acontecido en 1789". Cfr. GONZÁLEZ ALONSO, "La historia...", op. cit., pág. 27.

76 De la Cierva, Historia..., op. cit., t. VIII, pág. 19. 
nes los correspondientes derechos sucesorios. Según, en efecto, el citado artículo, "la Corona de las Españas y de las Indias será hereditaria en nuestra descendencia directa, natural y legítima, de varón en varón, por orden de primogenitura y con exclusión perpetua de las hembras»77.

Así pues, al margen de esta interrupción temporal (que terminó, lógicamente, con la derrota francesa y la expulsión de José Bonaparte), debe significarse que, a partir de 1789, la voluntad concorde de Rey y Cortes era la de derogar "la novedad hecha en el Auto Acordado" y volver al sistema tradicional de Las Partidas. Será, pues, este sistema el que, en esencia, recoja la Constitución de Cádiz de 1812, particularmente en el Capítulo II de su Título IV (artículos 174 a 184), que lleva como rúbrica "De la sucesión a la Corona»" 78 . A semejanza del célebre Código del Rey Sabio, el constituyente gaditano acoge, en efecto, los principios hereditario, de filiación legítima, de primogenitura, de representación, de masculinidad preferente y de propincuidad (si bien limitando, en la aplicación de este último, el número de llamamientos), principios a los que proporciona un desarrollo en detalle a través de los artículos $175^{79}, 176^{80}, 177^{81}, 178^{82}$ y $180^{83}$. Acepta, además, en el artículo 182 y con carácter subsidiario ( "si llegaren a extinguirse todas las líneas que aquí se señalan») una especie de principio electivo ( "las

77 El texto de la Constitución de Bayona puede leerse en TORRES DEL MORAL, A. y Rodriguez Coarasa, C., Monarquía y Constitución (II. Textos Jurídicos), Edit. Colex, Madrid, 2000, págs. 39-46.

78 Utilizamos para este trabajo los textos de las Constituciones históricas españolas según son recogidos en J. DE Esteban, Las Constituciones de España, Edit. Taurus, Madrid, 1982. Para la Constitución de Cádiz, vid. págs. 45 a 96.

79 Art. 175: "No pueden ser Reyes de las Españas sino los que sean hijos legitimos habidos en constante y legitimo matrimonion.

80 Art. 176: «En el mismo grado y línea los varones prefieren a las hembras y siempre el mayor al menor, pero las hembras de mejor linea o de mejor grado en la misma línea prefieren a los varones de línea o grado posterior".

81 Art. 177: "El hijo o hija del primogénito del Rey, en el caso de morir su padre sin haber entrado en la sucesión del reino, prefiere a los tíos y sucede inmediatamente al abuelo por derecho de representación».

82 Art. 178: "Mientras no se extingue la línea en que está radicada la sucesión, no entra la inmediatan.

83 Art. 180: "A falta del Señor Don Fernando VII de Borbón, sucederán sus descendientes legítimos, así varones como hembras: a falta de éstos, sucederán sus hermanos y tíos hermanos de su padre, asi varones como hembras, y los descendientes legítimos de éstos por el orden en que queda prevenido, guardando en todos el derecho de representación y la preferencia de las líneas anteriores a las posteriores". 
Cortes harán nuevos llamamientos como vean que más importa a la Nación»), cuya efectiva aplicación parece estar condicionada, sin embargo, por el principio de propincuidad, toda vez que las Cortes, para decidir el destinatario de esos nuevos llamamientos, han de seguir necesariamente "el orden y reglas de suceder aquí establecidas", lo que se traduce en que deben buscar al pariente más próximo del Rey fallecido.

Por lo demás, también se contemplan en el texto constitucional de 1812 dos supuestos de exclusión del orden sucesorio: el primero lo constituye, genéricamente, la incapacidad para gobernar; $y$ el segundo, aún más inespecífico, el de haber incurrido en algún demérito para ello ("que [...] hayan hecho cosa que merezcan perder la corona", según el tenor literal del artículo 181). Por último, el artículo 183 establece una presunción de renuncia al ejercicio regio o a la sucesión cuando, respectivamente, la Reina (no el Rey) o la Princesa de Asturias (no el Príncipe) contraigan matrimonio sin el previo consentimiento de las Cortes.

Tras pasar por múy diversas vicisitudes históricas ${ }^{84}$, la Constitución de Cádiz es finalmente declarada nula por el Rey Fernando VII en 1823, dando inicio a la llamada "década ominosa". Tal anulación supone -en lo relativo al tema sucesorio que nos interesa- la vuelta al estado anterior, esto es, a la vigencia formal del Auto Acordado

84 La vigencia de la Constitución de 1812 adolece de una acusada falta de continuidad. En un primer período, que va desde su promulgación hasta el regreso de Fernando VII, apenas si tuvo una vigencia efectiva por causa de la situación de guerra y de la ausencia del Rey. Esa escasa vigencia desaparece por completo cuando, tras recuperar el trono, el Rey dicta el Decreto de 4 de mayo de 1814, declarando nulos la Constitución y los Decretos de las Cortes “como si no hubiesen pasado jamás tales actos y se quitasen de en medio del tiempon. Volvió a recuperar su vigencia con el levantamiento militar de Riego de 1 de enero de 1820, que obligó a Fernando VII a jurar de nuevo la Constitución, dando inicio al Ilamado "trienio liberal». Por último, perdió su vigencia de forma definitiva cuando el Rey, desoyendo las recomendaciones de prudencia de las monarquías europeas reunidas en la llamada "Santa Alianza", decide volver al régimen absolutista de gobierno e iniciar una muy cruenta represión contra los liberales. Para ello contó con el apoyo de los absolutistas españoles y de un ejército francés ("Los Cien Mil Hijos de San Luis"), que invadió el territorio español el 7 de abril de 1823 y, sin encontrar apenas resistencia popular, culminó su acción con la tomá de Cádiz, donde se hallaba, como rehén de los liberales, el Rey Fernando VII, que tuvo finalmente que ser entregado al ejército francés el 1 de octubre de 1823. Datos extraídos de TORRES del Moral, Constitucionalismo histórico español, Servicio de Publicaciones de la Facultad de Derecho, Universidad Complutense, Madrid, 1998, págs. 49-53; y DE LA Cierva, Historia..., op. cit., t. VIII, págs. 226-228. 
de 1713. Esto no plantea mayores problemas hasta que, fallecida la Reina María Josefa Amalia de Sajonia, tercera esposa de Fernando VII, en mayo de 1829 y sin descendencia alguna, el Rey, pocos meses después de enviudar, contrae nuevo matrimonio ${ }^{85}$ con su prima María Cristina de Borbón ${ }^{86}$. Entonces, ante la eventualidad de tener descendencia femenina que se viera imposibilitada legalmente para reinar, decide dar cumplimiento al único requisito de eficacia que faltaba para derogar la "ley semisálica", es decir, el de publicar debidamente aquel acto de voluntad conjunto de Rey y Cortes con finalidad derogatoria, que - según hemos visto- quedó prácticamente ultimado en 1789. Para ello publica la Pragmática Sanción de 29 de marzo de 1830, que, no sin antes pasar por una serie de tremendos vaivenes políticos ${ }^{87}$, viene a restaurar el sistema sucesorio de la antigua Ley de Partida, que permitía - como hemos dicho- reinar a las mujeres en caso de que les correspondiera por su posición preferente en el orden de sucesión

85 La boda se celebró en Aranjuez el día 11 de diciembre de 1829. El Infante de mayor edad, Carlos Isidro, que en ese momento era el sucesor del Rey, y sus partidarios (los llamados "apostólicos", de ideología muy conservadora y defensores del absolutismol se opusieron frontalmente a la boda, pero, a pesar de la influencia que entonces tenía Don Carlos sobre su hermano el Rey, no consiguió modificar la voluntad de éste. Datos extraídos de DE LA CIERVA, Historia..., op. cit., t. VIII, págs. 232-233.

86 María Cristina era hija del Rey Francisco I de Nápoles y de la Infanta María Isabel, que ya tenian otra hija, Luisa Carlota, casada con el hermano menor de Fernando VII. Los liberales vieron en la futura Reina una firme valedora de sus expectativas politicas, por lo que crearon en su apoyo el partido "cristino", al que también se unirian algunos de los partidarios más moderados de Don Carlos. Datos extraidos de De LA Cierva, Historia..., op. cit., t. VIII, pág. 233.

87 Estos vaivenes políticos se condensan en una conocida historia acaecida en el Palacio Real de La Granja, durante el verano de 1832: habiendo caído gravemente enfermo el Rey Fernando VII y habilitada la Reina María Cristina para el despacho de los asuntos urgentes, el Infante Carlos Isidro hace pública su oposición a la Pragmática de 1830 y sus partidarios, con la complicidad del Barón Antonini, Embajador de Nápoles, y del Secretario de Gracia y Justicia, Francisco Tadeo Calomarde, coaccionan a los Reyes mediante la falsa amenaza de un levantamiento militar en favor del Infante y del consecuente estallido de una guerra civil, logrando arrancar del Rey enfermo, el 18 de septiembre de 1832, la firma de un Real Decreto derogando la citada Pragmática; María Cristina, inexperta y aterrada por el fantasma de la guerra civil, acepta el hecho consumado, pero la llegada, el 22 de septiembre, al Real Sitio de su hermana, la Infanta Luisa Carlota, cambia radicalmente el panorama: enfrentándose airadamente a Calomarde, al que llega a abofetear, consigue que rompa el mencionado Decreto; más adelante, ya parcialmente restablecido de su enfermedad, el Rey firma el 31 de diciembre de 1832 una declaración, por la que ratifica la anulación del Real Decreto. Datos extraídos de DE LA CIERVA, Historia..., op. cit., t. VIII, págs. 233-234. 
a la Corona. De este modo, quedaba abierta la puerta para que en el futuro pudiera acceder al trono la Infanta Isabel, primogénita del Rey, con las lamentables consecuencias que ello traería, en forma de guerras civiles, a todo lo largo del siglo $\mathrm{XIX}$.

A la muerte de Fernando VII (1833), con el subsiguiente acceso al trono de la citada Infanta Isabel, de dos años de edad, y la obligada regencia de María Cristina, viuda del Rey fallecido, desaparecen los obstáculos para que el régimen de Monarquía absoluta hasta entonces vigente pueda, por fin, encaminarse hacia el liberalismo. En este sentido, TORRES DEL MORAL Ilega, incluso, a calificar de «misterioson el hecho de que, tras el recalcitrante absolutismo de Fernando VII, quede como legado histórico de éste "una Monarquía abocada al liberalismo»88. El primer texto normativo, con el que el Gobierno del liberal Martínez de la Rosa intenta "un cierto reinicio del régimen constitucional ${ }^{89}$, es el Estatuto Real, que se promulga por Real Decreto de la Reina Gobernadora de 10 de abril de 1834, pero en dicho texto no se contempla nada relativo a la sucesión a la Corona, toda vez que sú regulación sobre la figura del Rey se ciñe exclusivamente a las facultades de éste en relación con las Cortes $^{90}$.

No será, por tanto, hasta tres años más tarde, al promulgarse la Constitución de 18 de junio de 1837, cuando el régimen sucesorio de la Corona encuentre una nueva regulación, si bien ésta se limita a reproducir, reduciendo el número de los preceptos dedicados al tema, las líneas maestras del régimen previsto en la Constitución de Cádiz. Así, en tan sólo seis artículos (del 50 al 55) del Título VII, bajo la rúbrica "De la sucesión a la Corona», el constituyente de 1837, tras proclamar a Isabel II como "la Reina legítima de las Españas» (art. 50), regula el mecanismo sucesorio sobre la base de los mismos principios ya recogidos en el texto constitucional precedente: el hereditario, el de primogenitura, el de representación y el de masculinidad preferente hallan su acomodo en el artículo $51^{91}$; los de filiación legítima y de pro-

88 Torres del Moral, A., Constitucionalismo..., op. cit., pág. 55.

89 lbidem, pág. 57.

90 Fundamentalmente, en el Título V (arts. 24 y ss.). Vid. el texto en DE ESTEBAN, Las Constituciones..., op. cit., págs. 97-103.

91 Art. 51: "La sucesión del Trono de las Españas será según el orden regular de primogenitura y representación, prefiriendo siempre la línea anterior a las posteriores; en la misma línea, el grado más próximo al más remoto; en el mismo grado, el varón a la hembra y, en el mismo sexo, la persona de más edad a la de menos". Obsérvese, por cierto, la enorme semejanza entre este texto y el del artículo 57.1 de la vigente Constitución de 1978. 
pincuidad (también con limitación de llamamientos), en el artículo 5292; y el electivo, en el artículo 53, a cuyo tenor "si llegasen a extinguirse todas las líneas que se señalan, las Cortes harán nuevos llamamientos, como más convenga a la Nación». Este último principio tiene, pues, al igual que en la Constitución de 1812, un mero carácter subsidiario, pero su régimen de aplicación efectiva difiere sustancialmente del previsto en dicho texto constitucional, toda vez que las Cortes, al hacer esos nuevos llamamientos, no se hallan condicionadas a seguir "el orden y reglas de suceder" establecidos, al contrario de lo que -según veíamos- disponía el artículo 182 de aquella Constitución. Quiere ello significar, en nuestra opinión, que el principio electivo pasó a gozar en 1837 de una operatividad plena, lo que, desde una perspectiva jurídica, debía traducirse en la existencia de un régimen de libre discrecionalidad, sin condicionante alguno, de las Cortes a la hora de ejercer su facultad constitucional de proveer a la sucesión de la Corona. No hubo, sin embargo, ocasión histórica alguna para poder comprobarlo.

Tampoco se separa la Constitución de 1837 de la de Cádiz en la previsión de los dos supuestos de exclusión del orden sucesorio: la incapacidad para gobernar y el haber "hecho cosa porque merezcan perder el derecho a la Coronan. Por el contrario, sí desaparece, respecto de la de 1812, la presunción de iure de renuncia al ejercicio regio o a la sucesión que se establecía en el artículo 183 para el supuesto de que, respectivamente, la Reina o la Princesa de Asturias contrajeran matrimonio sin la previa autorización de las Cortes.

Ocho años después, el régimen de sucesión a la Corona vuelve a ser objeto de regulación en la Constitución de 23 de mayo de 1845 , a través de los artículos 49 a 55, que contienen una normativa prácticamente idéntica a la del texto de 1837. Tan sólo difiere al añadir la necesidad de una ley especial aprobada en Cortes, tanto para hacer, en caso de agotarse las líneas sucesorias establecidas, "nuevos llamamientos, como más convenga a la Nación" (art. 52), como para excluir de la sucesión en los mismos dos casos ya contemplados en las Constituciones anteriores (art. 54). Una segunda y más relevante diferencia es la adición de un nuevo artículo para prever el supuesto de que se susciten dudas, de hecho o de derecho, respecto de la suce-

92 Art. 52: «Extinguidas las líneas de los descendientes legítimos de Doña Isabel II de Borbón, sucederán, por el orden que queda establecido, su hermana $y$ los tíos hermanos de su padre, asi varones como hembras, y sus legítimos descendientes, si no estuviesen excluidos". 
sión a la Corona, en cuyo caso deberán resolverse también mediante una ley ad hoc (art. 53). Como puede observarse, este artículo $53^{93}$ constituye un precedente directo del actual artículo $57.5 \mathrm{CE}$, aunque el objeto de éste sea de una mayor amplitud por abarcar también a las abdicaciones y renuncias.

La siguiente regulación de la sucesión a la Corona no se produce hasta después de la Revolución de 1868, con la Constitución aprobada $^{94}$ por las Cortes Constituyentes el 1 de junio de 1869 y promulgada ${ }^{95}$ cinco días después. En este nuevo texto ${ }^{96}$, que incluye en su Título V ("De la sucesión de la Corona y de la regencia del Reino») el reducido número de tres artículos (el 77 , el 78 y el 80 ) dedicados a dicha regulación, subyacen los mismos principios de las Constituciones anteriores, si bien no hay mención expresa de los principios de filiación legítima y de propincuidad. Los principios hereditario, de primogenitura, de representación y de masculinidad preferente quedan recogidos en el artículo $77^{97}$, mientras que el electivo y el de propincuidad lo hacen en el artículo $78^{98}$, debiendo este último principio entenderse implícito, a nuestro modo de ver, en la alusión hecha por el citado artículo a "la dinastía", concepto este que, aun no estando demasiado bien delimitado jurídicamente, cabe identificar con el conjunto de parientes del

93 Según su tenor literal, "cualquiera duda de hecho o de derecho que ocurra en orden a la sucesión de la Corona, se resolverá por una ley».

94 Una vez celebradas las elecciones a Cortes Constituyentes y constituidas éstas, el proceso de elaboración de la Constitución fue muy breve (tres meses), quedando ultimado el texto a finales del mes de mayo. Sometido a votación del Pleno el 1 de junio, resultó aprobado por 214 votos a favor, 55 en contra y algunas abstenciones. Datos extraídos de TORRES DEL MORAL, Constitucionalismo..., op. cit., pág. 100.

95 Al no haber en ese momento ningún titular de la Jefatura del Estado, pues la Reina Isabel II habia marchado a su exilio parisino, la promulgación del nuevo texto constitucional hubo de hacerse por las propias Cortes Constituyentes, en nombre de la nación española. Datos extraídos de TORRES DEL MORAL, Constitucionalismo..., pág. 100.

96 Para su lectura, vid. De Esteban, Las Constituciones..., op. cit., págs. 137-154.

97 Art. 77: «La autoridad real será hereditaria. La sucesión en el trono seguirá el orden regular de primogenitura y representación, siendo preferida siempre la línea anterior a las posteriores; en la misma línea, el grado más próximo al más remoto; en el mismo grado, el varón a la hembra, y en el mismo sexo, la persona de más edad a la de menos».

98 Art. 78: "Si llegare a extinguirse la dinastia que sea llamada a la posesión de la Corona, las Cortes harán nuevos llamamientos como más convenga a la Nación". 
Rey que descienden de su mismo tronco. $Y$ de ahí que esa obligación, impuesta por el artículo 78, de agotar los llamamientos a miembros de "la dinastía» antes de proceder a la designación del sucesor regio por las Cortes parezca, pues, abonar la tesis de la implicitud del principio de propincuidad en dicho artículo. Por su parte, el artículo 80 se limita a reproducir los dos supuestos de exclusión de la sucesión ya contemplados en las Constituciones anteriores, si bien desaparece, en relación con el texto constitucional anterior, la exigencia expresa de que la decisión parlamentaria al respecto revista forma de ley.

La última vez que, en el constitucionalismo histórico español del siglo XIX, aparece una normativa sobre la sucesión regia va a ser en la Constitución de la Restauración borbónica, de 30 de junio de 1876, cuyos artículos 59 a 64, dentro del Título VII ("De la sucesión a la Coronan), constituyen una reproducción casi literal de los artículos que, sobre la misma materia, se contenían en la Constitución de 1845 (es decir, los que iban del 50 al 54). Las únicas diferencias entre ambas regulaciones vienen originadas, lógicamente, por la sustitución de personas que se produce en la titularidad de la Jefatura del Estado. Así, la mención a Isabel II (del antiguo artículo 49) se hace ahora a Alfonso XII de Borbón, proclamándole el artículo 59 nuevo "Rey legítimo de España" (no de "las Españas"); y cambian, igualmente, las líneas llamadas a suceder en aplicación del principio de propincuidad, que recoge el artículo $61^{99}$. Salvo estos mínimos detalles, ambas normativas son -como decíamos- idénticas entre ellas $y$, a su vez, muy parecidas a la de la Constitución de 1837, por lo que, para evitar repeticiones, debemos remitirnos a lo dicho anteriormente al respecto.

Ya dentro del siglo XX, la única norma reguladora de la sucesión regia, anterior a la contenida en el texto constitucional vigente, es la que se encuentra en la Ley de Sucesión a la Jefatura del Estado de 26 de julio de 1947100, una de las siete leyes fundamentales que -como se sabe- rigieron, a modo de normas constitucionales, la estructura orgánica y el funcionamiento del régimen franquista nacido de la Guerra Civil. Según la declaración contenida en el primero de los artículos de la mencionada Ley, el Estado español quedaba, "de acuerdo con su tradición», constituido en Reino, si bien no se realizaba ninguna

99 Art. 61: «Extinguidas las líneas de los descendientes legítimos de Don Alfonso XII de Borbón, sucederán por el orden que queda establecido sus hermanas; su tía, hermana de su madre, y sus legitimos descendientes, y los de sus tíos, hermanos de Don Fernando VII, si no estuviesen excluidos".

100 Vid. su texto en De EsTEBAN, Las Constituciones..., op. cit., págs. 231-238. 
mención expresa ni a dinastía ni a persona alguna destinada a asumir, en su momento, el ejercicio regio, toda vez que se pretendía instaurar una nueva Monarquía, vinculada y comprometida con los llamados "Principios del Movimiento Nacional» y, por tanto, absolutamente independiente de la que reinara en España hasta 1931. No había, pues, por la temprana fecha de promulgación de la citada Ley fundamental, ninguna decisión legal que concretara o al menos permitiera determinar, de un modo cierto, la persona del futuro sucesor, a título de Rey, del General Franco en la Jefatura del Estado, aunque sí se detallaban los requisitos ${ }^{101}$ necesarios para poder optar, en su día, a la oportuna designación. Y, en lo que más nos interesa ahora, la Ley contenía en el apartado I de su artículo 11 una detallada regulación del mecanismo sucesorio, que tomaba a préstamo elementos tanto del orden sucesorio castellano (subsistente, según hemos visto, a todo lo largo de nuestro constitucionalismo histórico del siglo $X(X)$, como $-y$ he aquí la gran novedad- del antiguo sistema aragonés, legalmente olvidado desde mucho tiempo atrás ${ }^{102}$. De la castellana Ley de Partida tomaba, en efecto, sus mismos principios rectores (hereditario, de filiación legítima, de representación y de primogenitura), mientras que de la regulación sucesoria de la Corona de Aragón recogía el principio de masculinidad excluyente, con la consecuente prohibición del acceso al trono de las mujeres. Las previsiones contenidas en la Ley de Sucesión, complementadas posteriormente por la Ley de 22 de julio de 1969, de designación de D. Juan Carlos de Borbón como sucesor a título de Rey ${ }^{103}$, y por la Ley de 14 de julio de $1972^{104}$, tuvieron su efecti-

101 Los requisitos establecidos por el artículo 9 LSJE eran los siguientes: varón, nacionalidad española, mayor de treinta años y católico, además de "poseer las cualidades necesarias para el desempeño de su alta misión y jurar las Leyes fundamentales, asi como lealtad a los Principios que informan el Movimiento Nacional'. A tales requisitos, debía añadirse, según lo dispuesto en el artículo 8.1 LSJE, el de la pertenencia del candidato a una "estirpe regia".

102 Vid. supra, págs. 15 y 26 y notas núms. 28 y 49 . El sistema sucesorio aragonés dejó de tener vigencia efectiva con la centralización del poder político llevada a efecto por el primer Rey de la Casa de Borbón, Felipe V. No obstante, el Auto Acordado de 1713, en cuanto que establecía la llamada "ley semisálica" (que prohíbe, como se sabe, el acceso al trono de la mujer mientras existan varones en cualquiera de las líneas sucesorias), mantuvo una cierta semejanza con dicho sistema.

103 Vid. supra, nota núm. 6.

104 Mediante esta brevísima Ley, que consta de tan sólo cuatro artículos, se dictaron las normas relativas al procedimiento a seguir, una vez vacante la Jefatura del Estado, para el acceso a ella del entonces Príncipe de España, D. Juan Carlos de Borbón. Su texto puede consultarse en TORRES DEL MORAL y ROdríguez COARASA, Monarquía y..., op. cit., págs. 118-119. 
va aplicación sólo en la medida en que permitieron el acceso de este último a la Jefatura del Estado, tras la muerte del General Franco; y no en cuanto al orden sucesorio establecido por el referido artículo 11, que quedó derogado - sin que hubiera llegado, por fortuna, a tener ocasión de aplicarse- por la entrada en vigor de la Constitución de 1978.

La mirada retrospectiva que acabamos de efectuar a los entresijos de nuestra historia político-constitucional nos permite, en definitiva, llegar a la convencida conclusión de que la nueva regulación constitucional del orden sucesorio es deudora, en muy apreciable medida, del Derecho histórico español, fundamentalmente del castellano, pero no sólo de él, sino también del aragonés y del navarro. No puede olvidarse, en efecto, que tres de los principios informadores de la actual regulación (el hereditario, el de primogenitura y el de filiación legítima) son comunes a los tres Derechos; que el principio de representación rigió tanto en Castilla (desde Las Partidas) como en Aragón; y que el principio de masculinidad preferente, esto es, sin exclusión de la mujer en el acceso al trono, se recoge tanto en la castellana Ley de Partida como en el Fuero General navarro. Por su parte, el principio electivo (que consagra el artículo 57.3 CE) procede del constitucionalismo decimonónico, pues lo establece la Constitución de Cádiz y se reproduce en las posteriores. Y, para terminar, debemos también subrayar que la única diferencia sustantiva entre la regulación constitucional y el Derecho histórico la constituye la inaplicación, en la actualidad, del principio de propincuidad como regla subsidiaria de provisión de la Corona, en defecto de descendientes directos del Rey.

\subsubsection{Derecho comparado}

Tras el enfoque realizado sobre el Derecho histórico español, procede ahora fijar nuestra atención en algunos de los Estados de nuestro entorno europeo occidental (concretamente, los reinos de Bélgica, Holanda, Dinamarca, Noruega y Suecia), pues sólo en ellos se encuentran asentadas, con la salvedad del lejano Japón, las escasas monarquías parlamentarias que subsisten en el mundo actual. Ello no tiene otro objeto que hacer un estudio comparativo de nuestro régimen constitucional de sucesión a la Corona con las homólogas regulaciones existentes en dichos Estados.

El primer elemento normativo que es común a todos sus regímenes sucesorios (y también, por supuesto, al español) lo constituye la aceptación del principio hereditario, con constancia expresa, ade- 
más, de los nombres de los distintos reyes que encabezan las respectivas dinastías (con la sola excepción de Noruega) ${ }^{105}$ : el Rey LéopoldGeorges-Chrétien-Fréderic de Saxe-Cobourg, en Bélgica ${ }^{106}$; el Rey Christian y la Reina Alexandrine, en Dinamarca ${ }^{107}$; el Rey Guillermo I, Príncipe de Orange-Nassau, en Holanda ${ }^{108}$; y el Rey Carlos XVI Gustavo, en Suecia ${ }^{109}$. En caso de extinción de las líneas sucesorias directas, se abre un no muy extenso abanico de soluciones. Así, en la Constitución belga se permite al Rey, con el asentimiento de las Cámaras legislativas, nombrar su sucesor; en defecto de este nombramiento, el trono se declara vacante al morir el Rey, designando entonces las Cámaras un Regente provisional y disolviéndose de inmediato; finalmente; tras constituirse las nuevas Cámaras, éstas proceden, en sesión conjunta, a nombrar al sucesor del Rey difunto ${ }^{110}$. Parecida solución a la belga, aunque menos complicada, se establece en la Constitución noruega de $1814^{111}$. En Dinamarca, por el contrario, se aplica el principio de propincuidad, sucediendo al Rey, si no hubiere descendientes propios, las líneas encabezadas por sus hermanos y, en su defecto, la línea colateral más próxima112. La misma solución danesa se adopta en Holanda, si bien limitando la aplicación del principio de propincuidad al tercer grado de parentesco con el Rey difunto ${ }^{113}$. Por último, en la Ley de Sucesión sueca de 1810 no existe ninguna previsión al respecto; en otra de las Leyes fundamentales, la Ley sobre la For-

105 El artículo 6.3 de la Constitución del Reino de Noruega, de 17 de mayo de 1814, se limita a decir que "no tendrán derecho a la sucesión las personas no nacidas en la línea directa de sucesión de los últimos Rey o Reina reinantes".

106 Artículo 85.1 de la Constitución belga de 17 de febrero de 1994.

107 Artículo 1 de la Ley núm. 170, de Sucesión al Trono, de 27 de marzo de 1953, que figura como Anexo de la Constitución del Reino de Dinamarca, de 5 de junio de 1953.

108 Artículo 24 de la Constitución del Reino de los Países Bajos, de 17 de agosto de 1983.

109 Artículo 1 de la Ley de Sucesión, de 26 de septiembre de 1810 (reformada en 1980).

110 Artículos 86 y 95 de la Constitucióni belga de 17 de febrero de 1994.

111 Según su artículo 7, "en el caso de que no hubiere Princesa o Príncipe con derecho a sucesión, el Rey podrá proponer un sucesor al Storting [Parlamento noruegol, que tendrá derecho a efectuar la elección si la propuesta del Rey no fuera aceptada».

112 Artículos 3 y 4 de la Ley de Sucesión al Trono de 1953.

113 Según el artículo 25 de la Constitución holandesa, wa falta de descendientes propios, la Corona se transmitirá de la misma manera a los descendientes legítimos, en primer lugar a los del padre del Rey y a los de su abuelo, que estén en la línea de sucesión $y$ siempre que el grado de parentesco con el Rey difunto no sea superior al terceron. 
ma de Gobierno (Regeringsformen), si se contempla el nombramiento de un Regente por el Parlamento sueco en caso de "extinción de la Casa Real", pero ello no da tampoco una solución definitiva al problema sucesorio ${ }^{114}$.

La aplicación del principio de primogenitura constituye también pauta común en todos los regímenes sucesorios sometidos a comparación. Así, lo mencionan de forma expresa el artículo 85 de la Constitución belga, el artículo 2 de la Ley de Sucesión danesa, el artículo 25 del texto constitucional holandés, el artículo 6 del noruego y el artículo 1 de la Ley de Sucesión sueca. E igual cabe decir del derecho de representación de los descendientes del cabeza de línea premuerto, que es reconocido por los mismos preceptos que se acaban de citar, con la sola excepción del artículo 85 de la Constitución belga, que no hace alusión alguna al principio de representación, limitando su mención exclusivamente al "orden de primogenitura".

Sí se refiere, en cambio, este último artículo expresamente al principio de filiación legítima, cuando habla de "la descendencia directa, natural y legítima" del Rey, y lo mismo hacen el artículo 5 de la Ley de Sucesión danesa115, el artículo 24 de la Constitución de los Países Bajos $^{116}$ y el artículo 6 de la noruega ${ }^{117}$. Por el contrario, no recoge de forma expresa este principio la Ley de Sucesión sueca, aunque puede considerarse que se halla implícito en su artículo 5, cuando exige la previa autorización del Gobierno para el matrimonio del sucesor del Rey, castigando la omisión de este trámite con la pérdida de los derechos sucesorios para el contrayente y sus sucesores. Parece claro que, si la celebración del matrimonio principesco se envuelve de tan enorme rigidez formal, no menor debe ser la relativa al nacimiento de los sucesores del Rey. En otras palabras, la admisión de hijos no matrimoniales en el orden sucesorio sería esencialmente incoherente con la regulación tan estricta y de consecuencias tan relevantes, que se contiene en el citado artículo.

114 Según el artículo 4 de la Ley sobre la Forma de Gobierno, "en caso de extinción de la Casa Real, el Riksdag designará un Regente, que asumirá hasta nueva orden las funciones de Jefe de Estado y designará, al mismo tiempo, un Vicerregente».

115 Según su tenor literal, «solamente los hijos nacidos de un matrimonio legal tendrán derecho a heredar el trono".

116 Según su tenor literal, «la Corona es hereditaria en los sucesores legítimos del Rey Guillermo I, Príncipe de Orange-Nassau».

117 Según su tenor literal, «sólo tiene derecho a sucesión un descendiente nacido del matrimonio legal del Rey y de la Reina [...]". 
La cuasi-unanimidad existente en torno a los cuatro principios referidos se rompe, sin embargo, en lo relativo al principio de masculinidad preferente, que sólo recoge en la actualidad la Ley danesa de Sucesión al Trono, cuyo artículo 2 declara la "precedencia" del hijo sobre la hija ${ }^{118}$. En las Constituciones belga, holandesa, noruega y sueca (estas dos últimas, tras sus respectivas reformas de 1990 y 1980) se respeta la regla general de la igualdad entre varones y mujeres.

Así pues, cabe observar, en conclusión, una notable semejanza entre los regímenes sucesorios analizados y el tratamiento dado al tema por el constituyente español. La mayor diferencia viene representada por la aceptación en el artículo 57.1 CE del principio de masculinidad preferente, lo que, dada la fecha de promulgación de nuestra norma suprema, quizás pudiera ser tachado de anacrónico. No obstante, piénsese que en tal fecha no existían aún las actuales Constituciones belga (que es de 1994) y holandesa (que es de 1983) ni se habían producido las reformas de las Constituciones noruega y sueca, que implicaron, precisamente, la desaparición de la preferencia del varón sobre la mujer en el orden sucesorio. En la nueva redacción del artículo 6 de la Constitución noruega se recogió, sin embargo, una especie de disposición transitoria, mediante la que se respetaba el derecho preferente a suceder de los varones nacidos antes de 1990, fecha de la reforma. Y quizás hubiera sido ésta, como sugiere el Profesor TORRES DEL MORAL ${ }^{119}$, la mejor solución para nuestra regulación constitucional del orden sucesorio: respetar el derecho preferente del Príncipe de Asturias, D. Felipe de Borbón, y proveer, de cara al futuro, la igualdad de varones y mujeres en el orden de sucesión a la Corona.

\subsubsection{Causas de exclusión}

El orden de sucesión a la Corona no es - como ya se ha expuesto- inalterable, sino que puede verse sucesivamente modificado en el transcurso del por lo general largo período de tiempo que va desde el inicio de un reinado hasta el momento en que se produce la situación de vacancia regia, sea por causa de fallecimiento o de abdicación.

118 Paralelamente, en el artículo 3 de la misma Ley sucesoria se establece la preferencia del hermano del Rey sobre la hermana para sucederle en caso de que muriera sin descendencia.

119 Vid. TORRES DEL Moral, "La sucesión a la Corona...", op. cit., pág. 196. 
Algunas de estas modificaciones tienen su causa en la exclusión de alguna de las personas potencialmente llamadas a suceder, exclusión que, a su vez, puede ser de carácter voluntario o estar basada en razones de legalidad (incluyendo en éstas las que tienen su origen tanto en normas constitucionales como en normas de menor rango). La exclusión voluntaria es la que deriva, obviamente, de una declaración de voluntad de la persona integrante del orden sucesorio, que decide, con plena libertad y por el motivo que estime oportuno, renunciar a su condición de potencial titular de la Corona. A los problemas teóricos que plantea esta renuncia dedicaremos más adelante nuestra atención. Por su parte, la exclusión por razones de legalidad puede tener su causa en normas legales (como sería el caso de una permanente incapacidad de obrar de la persona que aspira a la sucesión regia) o en normas constitucionales.

Aunque la "inhabilitación para el ejercicio de su autoridad" sólo es reconocida por el texto constitucional en relación con el Rey (art. 59.2 CE), tratándola como una incapacidad sobrevenida que requiere su reconocimiento formal por las Cortes Generales, no cabe duda de que esa misma inhabilitación para el ejercicio regio puede producirse con anterioridad a tal ejercicio y exige, en nuestra opinión, su debido tratamiento jurídico, en el sentido de que la persona naturalmente incapacitada para ser Rey (a causa, por ejemplo, de una enfermedad mental incurable) debe ser excluida del orden de sucesión ${ }^{120}$, mediante un procedimiento que garantice debidamente sus derechos. El fundamento legal para dicha exclusión se hallaría, no en el texto constitucional, que no la prevé, sino en las normas legales que, con carácter general, regulan el acceso a los cargos públicos. Al ser, en efecto, el cargo de Jefe del Estado el de mayor relevancia dentro de los denominados "cargos públicos», parece lógico aplicar las normas generales de capacidad para el desempeño de los mismos, de tal manera que, si quedara acreditada la permanente incapacidad de obrar de un suce-

120 En contra, A. PÉreZ de ARMiŃÁN, para quien, salvo en el caso de infracción de la prohibición prevista en el artículo $57.4 \mathrm{CE}$, «no existe [...] la posibilidad de excluir de la sucesión a los descendientes de Don Juan Carlos l que se hubieren inhabilitado", optando en este supuesto por la solución de que las Cortes proclamen al sucesor como Rey, si bien reconociendo simultáneamente su incapacidad para el ejercicio regio y aplicando, de inmediato, las previsiones constitucionales sobre la regencia. La posibilidad de inhabilitación por las Cortes sólo la admite para los parientes llamados a la sucesión por aplicación del principio de propincuidad, en defecto de descendientes del Rey. Vid. PÉREZ DE ARMIÑÁN Y DE LA SERnA, "La dinastía...", op. cit., pág. 112. 
sor del Rey, éste debe quedar excluido del orden sucesorio. No se trata, sin embargo, de excluir a cualquier candidato a la sucesión regia que sea considerado incapaz para el ejercicio de un cargo público, pues ello equivaldría a poner en funcionamiento, sin que exista una inmediata necesidad, un complicado mecanismo legal para su inhabilitación; se trataría, por el contrario, de restringir el procedimiento inhabilitante al supuesto de una incapacidad permanente del Príncipe heredero, en cuanto que único titular de un derecho subjetivo a suceder en el trono al monarca reinante, 0 , a lo sumo, del situado en la lista sucesoria inmediatamente detrás del Príncipe.

Ahora bien, es claro que ello exige un procedimiento garantista, que, dadas las consecuencias tan relevantes que, desde la perspectiva constitucional, conlleva, debe tramitarse por las Cortes Generales, como órgano representativo del pueblo soberano, y culminar en un acto parlamentario que, tras dejar constatada la existencia de una incapacidad de obrar permanente, declare la exclusión de la persona que la padece del orden de sucesión a la Corona. Tal acto podría revestir forma de Resolución ${ }^{121}$, ya que ésta constituye, al no estar previsto expresamente otro, el cauce formal ordinario para la expresión de los actos parlamentarios de carácter no normativo. Además, dicha Resolución podría ser conjunta de ambas Cámaras, si se aplica por analogía lo dispuesto en el artículo 74.1 CE para el ejercicio de las competencias no legislativas asignadas a las Cortes por el Título II de la Constitución ${ }^{122}$. La exclusión, por último, no debe afectar a los descendientes actuales del incapacitado por aplicación del principio de representación, que rige, según hemos visto, el orden sucesorio (art. 57.1 CE).

Frente a este supuesto no previsto constitucionalmente, el artículo 57.4 CE sí contempla un caso de exclusión: "Aquellas personas que, teniendo derecho a la sucesión en el trono, contrajeren matrimonio contra la expresa prohibición del Rey y de las Cortes Generales quedarán excluidas en la sucesión a la Corona por sí y sus descendientes". Se trata, según cabe deducir de su simple lectura, de un precepto de carácter sancionador o punitivo, en cuya virtud se condiciona la continuidad en el orden sucesorio al cumplimiento de un

121. A. TORRES DEL. MORAL admite también la forma de ley orgánica sobre la base de que se considere como un caso de duda sobre el orden de sucesión, si bien reconoce que esa no es "la interpretación literal e inmediata del precepto constitucional». Cfr. ToRres del Moral, El Príncipe..., op. cit., págs. 176-177.

122 En este sentido, TORRES DEL MORAL, ibidem. 
supuesto deber de abstención: el de no contraer matrimonio frente a la doble prohibición de Rey y Cortes. No es correcta, por cierto, la utilización del término "prohibición", pues implicaría que lo actuado en su contra se sancionaría con la nulidad. El constituyente tendría que haberse referido a una "oposición" formal del Rey y de las Cortes ${ }^{123}$. En cualquier caso, lo que no hay es una exigencia de previa autorización para contraer matrimonio, ya que éste seguirá siendo válido aunque se contraiga desoyendo la prohibición. Ahora bien, el aludido precepto constitucional es indudable que juega en un sentido finalísticamente muy parecido, en cuanto que viene a uamenazar" al candidato, que pretenda casarse en contra del parecer del Rey y de las Cortes, con alejarlo de la posibilidad de ser llamado a la sucesión.

El precepto parece implicar, además, la obligación por parte del futuro contrayente de poner en conocimiento del Rey y de las Cortes su intención de contraer matrimonio con la antelación necesaria para que uno y otras puedan ejercer, en caso de que lo estimen conveniente, su respectiva facultad de oponerse al mismo. Caso de que no cumpliera con esa obligación de informar o de que contraiga matrimonio secreto, algún sector doctrinal ${ }^{124}$ ha abogado por la posibilidad de prohibir a posteriori el matrimonio ya válidamente celebrado, con el mismo efecto punitivo previsto en el artículo 57.4 de nuestra ley fundamental. A nuestro modo de ver, sin embargo, no es posible la aplicación de este artículo por vía de analogía o de interpretación extensiva, precisamente por ese carácter punitivo o de sanción que, sin duda, tiene. Para llegar a la solución doctrinalmente propugnada se necesitaría, por tanto, que el caso antes referido de falta de comunicación o de matrimonio secreto del candidato a la sucesión regia fuera expresamente previsto y regulado en sus consecuencias jurídicas como uno más de los casos dudosos a resolver por ley orgánica, según lo dispuesto en el apartado 5 del repetido artículo $57 \mathrm{CE}$.

Otra cuestión sumamente interesante que cabe plantear en este punto es la relativa al modo de formalizarse esa doble oposición al matrimonio que se pretende contraer. En este sentido, entendemos que el acto de prohibición del Rey, en cuanto que, a tenor de lo dispuesto en el artículo $64 \mathrm{CE}$, ha de ser refrendado por el Presidente del

123 En este sentido, Gómez SÁnCHez, "Matrimonios regios...", op. cit., pág.

199.

124 Gómez SÁNCHEZ, ibidem. 
Gobierno, requiere un Real Decreto para su debida formalización jurídica. Más discutible resulta la determinación del cauce formal de expresión del acto parlamentario de prohibición. No puede ser, a nuestro juicio, una ley orgánica, pues no entra dentro de los supuestos previstos en el artículo 57.5 CE (abdicaciones, renuncias y dudas de hecho o de derecho sobre la sucesión). Lo más apropiado quizás sería que adoptara la forma de una Resolución conjunta de ambas Cámaras, toda vez que, según lo dispuesto en el artículo 74.1 CE, éstas "se reunirán en sesión conjunta para ejercer las competencias no legislativas que el Título Il atribuye expresamente a las Cortes Generales".

\subsection{Las abdicaciones y las renuncias}

Si en relación con la figura del Príncipe heredero el constituyente no se distinguió, precisamente, por su generosidad normativa, en el tratamiento de las abdicaciones y de las renuncias podría decirse que su «tacañería" se acentúa aún más, por cuanto se limita a mencionarlas en el apartado 5 del artículo 57 CE y a remitir su "resolución» a una futura ley orgánica. Desde un punto de vista simplemente gramatical, la redacción de este apartado deja ya bastante que desear, pues lo que literalmente dispone, si dejamos al margen la alusión a las dudas que puedan surgir en torno al mecanismo sucesorio, es que "las abdicaciones y renuncias [...] se resolverán por ley orgánica". ¿Qué quiere decir nuestro constituyente cuando utiliza el mismo verbo («resolver») para las dudas que para las abdicaciones y renuncias? Porque es evidente que las dudas pueden resolverse, pero no así las abdicaciones y renuncias, que exigen, en un uso correcto del idioma español, otro verbo distinto para expresar la intención del constituyente sobre las mismas. Quizás este error gramatical se deba a haber asumido el tenor literal del precepto paralelo contenido en las Constituciones de 1845 y 1876, a pesar de que sólo se hallaba referido a las dudas y no a las abdicaciones y renuncias. $O$, por el contrario, también podríamos plantearnos que fuera realmente su intención que éstas deban "resolverse" o "solucionarse" mediante la elaboración de una ley orgánica. $Y$, en tal caso, ¿se trata de una ley orgánica para cada ocasión en que se produzca una abdicación regia o una renuncia al derecho o a la expectativa de suceder al Rey? Como se observa, el caudal de dudas que genera la redacción del apartado 5 no es, ciertamente, pequeño.

En principio, una interpretación lógica del precepto referido debe llevar a que no existen razones que impidan la elaboración de una ley 
orgánica que regule, con carácter general, esta materia. Cabe preguntarse, sin embargo, si la intención del constituyente es que, junto a esta regulación general, exista una ley orgánica en cada caso concreto de renuncia (concepto que engloba al de abdicación, pues ésta, jurídicamente hablando, no deja de ser una renuncia). $Y$ en el supuesto de que esto fuera cierto, ¿qué función cumple la concreta ley orgánica que en cada caso se elabore?

La respuesta a esta serie de preguntas debe derivar, en nuestra opinión, del estudio de la regulación genérica que sobre la renuncia de derechos se contiene en el artículo 6.2 del Código Civil, cuyo contenido no es específico del orden civilístico privado, como a primera vista pudiera deducirse de su ubicación legal, sino que, por el contrario, debe resultar aplicable a todos los sectores del ordenamiento jurídico, en cuanto que materia propia de la teoría general del Derecho. Según el citado artículo, sólo será válida "la renuncia a los derechos [...] cuando no contraríe el interés o el orden público ni perjudique a terceros". Del texto transcrito, deben ser significados, con vistas a lo que particularmente ahora nos interesa, los términos "derechos" e «interés público».

El primero de los citados términos nos lleva a una delimitación conceptual importante, porque, si bien el Rey cuando abdica renuncia a su derecho a seguir reinando y el Príncipe heredero puede, asimismo, renunciar a su derecho de acceder en un futuro al trono, todos los demás que siguen al Príncipe en el orden de sucesión no son titulares de un derecho subjetivo, sino tan sólo de expectativas de derecho. La cuestión se centra entonces en si pueden ser equiparables, a efectos de la previsión del artículo $57.5 \mathrm{CE}$, ambos tipos de renuncia. A nuestro modo de ver, la respuesta debe ser negativa, porque no pueden tener igual tratamiento constitucional las renuncias de derechos (como las del Rey y del Príncipe) que las de simples expectativas. Sería, además, absurdo dedicar el trabajo de las dos Cámaras parlamentarias a un asunto que podríamos llamar "menor", dado que el acto de renuncia a una expectativa a la sucesión regia sólo puede tener una muy lejana incidencia en el campo de lo público. Dicho acto modifica, sin duda, esa hipotética lista ordenada de aspirantes a la sucesión regia, pero constitucionalmente tal modificación tiene muy escasa relevancia, dado que en el lugar del renunciante figurará de inmediato la persona que le seguía en el orden sucesorio establecido. De ahí que nos inclinemos por considerar necesaria la ley orgánica exclusivamente en los casos de renuncia del Rey (o sea, de abdicación) o del Príncipe heredero. 
Ahora bien, aun reduciendo a estos dos supuestos la necesidad de ley orgánica, debemos preguntarnos por el papel que ésta representa. La respuesta nos la da el segundo término al que antes nos referíamos: el de "interés público". En efecto, dado que, según lo dispuesto en el artículo $6.2 \mathrm{CC}$, la renuncia contraria a dicho interés ha de reputarse nula, el papel de la ley orgánica en estos dos casos de renuncia aparece meridianamente claro: se trata del envoltorio jurídico-formal del acto de valoración realizado por las Cámaras legislativas sobre si la abdicación regia o la renuncia del Príncipe heredero es o no contraria al interés público. Según sea el resultado de esa valoración, se autorizará o no el acto de abdicación o de renuncia.

En lo que respecta a la abdicación, la solución que damos es congruente, aunque no se identifica, con la que ha sido tradicionalmente en nuestro Derecho la justificación doctrinal de la necesidad de autorización por las Cortes Generales del acto de abdicación ${ }^{125}$, exigencia ésta que se incorpora, además, al texto de las Constituciones españolas del siglo XIX, algunas de las cuales aluden expresamente a una "ley especial» para dar cobertura jurídica al acto parlamentario de autorización. Es éste el sentido que, en nuestra opinión, tiene la disposición constitucional de que "las abdicaciones y renuncias [...] se resolverán por ley orgánica", gramaticalmente incorrecta, según ha quedado ya expuesto.

Estrechamente ligada a la solución aportada va la cuestión sobre el momento de producción de efectos de los actos de abdicación y renuncia, que, en lógica consecuencia de lo expuesto, estarán condicionados en su eficacia a la promulgación y publicación de la ley orgánica en que se formalice el acto parlamentario de autorización. La

125 Según afirma TOMÁS VILLARROYA, "la doctrina política y la tradición constitucional españolas han entendido de consuno que el Rey, para abdicar, necesita estar autorizado por la nación y, más precisamente, por su representación en las Cortes. El principio doctrinal se ha apoyado fundamentalmente en la existencia de un pacto entre el Rey y su dinastía, de una parte, y la nación, de otra". A este argumento, puede añadirse el de la concepción del ejercicio regio como una obligación legal ("no es licito al Rey abdicar con la libertad del que [...] arroja al suelo la carga que oprime sus hombros", decía ColmeIRo) y el argumento histórico de la nulidad de la cesión del trono a Napoleón, hecha en Bayona por Fernando VII y Carlos IV, nulidad que derivaba no sólo de la violencia o coacción ejercida sobre éstos, sino principalmente - según ARGÜELLES- "por falta de consentimiento de la nación». Vid. TOMÁs VILLARROYA, J., "Las abdicaciones y renuncias", en su Comentario al artículo 57.5, dentro de Comentarios..., op. cit., págs. 160-161. 
abdicación, como acto unilateral de renuncia al ejercicio de un cargo público, no tiene más efecto que el de la vacancia del mismo, por lo que, a partir de entonces, procede que se cubra de acuerdo con las normas constitucionales reguladoras de la sucesión a la Corona. Es decir, el Rey no abdica en el Príncipe Heredero, sino que, al abdicar, deja vacante la Jefatura del Estado, que pasará a ser ocupada, sin solución de continuidad $y$ en virtud de lo dispuesto en un precepto constitucional, por el Príncipe Heredero. Y ello porque -como afirma el Profesor PÉREZ SERRANO- "la transmisión de la Corona se efectúa ope legis $y$ en el seno de una familia (dinastía) cuyos miembros ostentan derecho a ocupar el trono en caso de vacante, según el orden al objeto establecido» ${ }^{126}$.

Cabe aquí plantear dos interesantes cuestiones. La primera es la relativa a si conserva el abdicante, caso de que fuere ascendiente directo del nuevo Rey, un lugar en el orden de sucesión de éste, toda vez que los ascendientes en el sistema sucesorio civil pueden ser herederos del causante en determinados casos. La segunda cuestión se refiere, por su parte, a la posibilidad de que, después de haber abdicado, el ex Rey tuviera un hijo: ¿podría éste integrarse en el orden de sucesión a la Corona? Parece claro que la resolución de la primera cuestión planteada debe dar la clave, a su vez, para resolver la segunda.

En orden, pues, a resolver esa primera cuestión, debemos señalar que, en nuestra opinión y al margen de la evidente contradicción que la respuesta afirmativa implicaría con la conocida "doctrina de los propios actos" (de posible, aunque no segura, aplicación al caso planteado), la efectividad del principio de primogenitura, rector - como se sabe- del régimen constitucional sucesorio, se opone frontalmente a que el abdicante pueda situarse en el orden de sucesión al nuevo Rey, ocupando, en lo que es un mero planteamiento teórico, el lugar que corresponde a los ascendientes del causante en la sucesión intestada, es decir, a falta de descendientes. En cuanto al hijo nacido tras la abdicación, al no ser, obviamente, descendiente del actual Rey ni hallarse su padre (el Rey abdicante) entre las personas integrantes del orden sucesorio de la Corona, resulta claro que tampoco puede aspirar a ocupar lugar alguno en dicho orden.

126 Pérez Serrano, N., Tratado de Derecho Político, Edit. Civitas, Madrid, 1976, pág. 285. 


\section{DUDAS EN TORNO AL ORDEN DE SUCESIÓN A LA CORONA}

Dispone el artículo 57.5 CE que "cualquier duda de hecho o de derecho que ocurra en el orden de sucesión a la Corona se resolverán por una ley orgánica». Como ya quedó expuesto, esta rernisión a la ley orgánica podría entenderse hecha a una norma gene' al que regule apriorísticamente todos los aspectos conflictivos o polémicos que puedan surgir en relación con el orden de sucesión (y también, por supuesto, en relación con las abdicaciones y renuncias, a las que dicho artículo hace igualmente referencia). Y ello a pesar de que la redacción del precepto parece aludir a una ley específica para resolver cada una de las dudas que se planteen, ley que, en cualquier caso, no debe considerarse incompatible con aquella norma general. Ahora bien, hay que tener en cuenta dos consideraciones al respecto.

La primera de ellas es que esa ley orgánica general puede prever y dar una solución jurídica a cualquier duda de derecho que actualmente se plantee en relación con el orden sucesorio, pero no puede hacer lo mismo con las dudas de hecho, ya que esta categoría sólo comprende las que recaen sobre el efectivo acaecimiento de un determinado hecho que, de producirse, es jurídicamente relevante para el orden de sucesión a la Corona, por lo que a lo más que puede aspirar es a fijar la instrumentación jurídica necesaria para llegar a la comprobación del hecho objeto de la duda. De ahí que para resolver una duda de hecho sea siempre necesaria una ley orgánica específica que, en cumplimiento de lo que, en su caso, pueda disponer la norma general sobre los medios probatorios a utilizar, tenga como finalidad comprobar si el hecho dudoso se ha producido o no en la realidad, determinando, si ha lugar, la modificación subsiguiente en el orden sucesorio.

Algo semejante, pero no exactamente igual, y ésta es la segunda consideración que debemos hacer, ocurre con las dudas de derecho que pueden surgir en el momento actual, es decir, antes de esa futura ley orgánica que eventualmente se elabore para solucionar las dudas de este tipo que, en pura hipótesis, cabría plantear en la fecha presente. Obviamente, si se dictara dicha ley en el futuro, lo que ahora son dudas de derecho dejarían de serlo para pasar a la categoría de presupuestos de hecho de las distintas normas jurídicas destinadas a resolver aquellas dudas, bastando entonces con aplicar las consecuencias jurídicas que correspondan a la producción fáctica del supuesto previsto. Ahora bien, esa ley orgánica general, como es de lógica, no puede prever absolutamente todas las contingencias posi- 
bles en relación con la materia regulada, por lo que debe admitirse la posibilidad de que surjan nuevas dudas de derecho por no encajar la situación planteada en ninguno de los presupuestos de hecho previstos en dicha ley orgánica. Ello exigirá entonces la elaboración de leyes orgánicas específicamente destinadas a resolver tales dudas, de conformidad con lo dispuesto en el artículo 57.5 CE.

Hecho este planteamiento general y para dar fin a nuestro trabajo, vamos ahora a fijar la atención en tres de las más interesantes dudas de derecho, dentro de las muchas que podrían surgir actualmente al estudiar la normativa sobre el orden de sucesión a la Corona: el carácter exhaustivo o no de la lista sucesoria; la posibilidad de que los hijos adoptivos del monarca se integren en el orden de sucesión, en concurrencia con los hijos biológicos; y la posibilidad de que la elección del Rey por las Cortes Generales implique una mutación constitucional. Analicemos cada una de ellas por separado.

\subsection{La exhaustividad de la lista sucesoria}

Denominamos «lista sucesoria» a esa hipotética relación de candidatos a la sucesión regia, en la que éstos aparecen ordenados según los criterios de preferencia fijados por el artículo 57.1 CE. Dicha lista se integra, lógicamente, por los "sucesores" de S.M. Don Juan Carlos I de Borbón, según el tenor literal del mencionado artículo, que, junto a la proclamación de la nueva Monarquía y de su primer titular en ejercicio, a la que ya hicimos referencia, viene a establecer una nueva dinastía encabezada y fundada por ese primer titular de la Corona. Jurídicamente, pues, se trata de una nueva dinastía, aunque ello no sea óbice para que, además, se dé la coincidencia histórica de que su fundador enlace con la dinastía reinante en España durante casi tres siglos. En este sentido, debemos recordar aquí la afirmación, ya hecha con anterioridad, de que D. Juan Carlos I es Rey porque así lo decidió el constituyente, no por ser el «legítimo heredero de la dinastía histórica".

Ahora bien, la cuestión estriba en determinar quiénes son los "sucesores", ya que la inconcreción del texto favorece, sin duda, la formulación de distintos planteamientos doctrinales al respecto. Cabe aquí, en efecto, para dar una solución al problema remitirse a las normas del Código Civil sobre la sucesión intestada o, incluso, a las normas que tradicionalmente han regido el orden de sucesión dentro de la dinastía histórica. En nuestra opinión, sin embargo, no hay que remi- 
tirse a ningún otro cuerpo de normas (salvo en lo relativo a los conceptos técnicos, en los que debe remitirse a las normas del Código Civil), porque la solución se halla en el propio artículo 57.1 CE.

Para determinar qué debe entenderse por "sucesores" del Rey basta leer este articulo y fijarse en que el constituyente, al establecer los criterios determinantes del orden sucesorio, sigue, en líneas generales, los mismos que ya regian para la Corona de Castilla desde Las Partidas ( $y$ esencialmente reproducidos en todas las Constituciones españolas del siglo XIX), pero se aparta de éstas en lo relativo al principio de propincuidad (en cuya virtud, se llama al pariente más cercano, a falta de descendientes del Rey), al que sustituye por el principio electivo. Esta opción constitucional no puede ser desconocida y aparece, además, con una claridad meridiana en el artículo 57.3 CE: extinguidas las líneas llamadas en Derecho, son las Cortes las que han de proveer a la sucesión en la Corona. Y las líneas sólo pueden ser llamadas mediante la aplicación de los criterios establecidos por el artículo 57.1 CE, entre los que están el hereditario, el de primogenitura y el de consanguinidad (implícito en el anterior), pero no el de propincuidad, aunque algún sector doctrinal ${ }^{127}$ propugne la implicitud de éste en la mención a la "dinastía histórica" que hace el referido artículo.

Por tanto, a nuestro modo de ver, los sucesores del Rey D. Juan Carlos I sólo pueden encontrarse en las personas vinculadas a éste por filiación natural (excluyendo la adoptiva, según se argumentará más adelante) y matrimonial y que conforman el núcleo básico familiar estructurado en torno a su persona, esto es, la Familia Real. La sustitución del principio de propincuidad por el electivo opera así como mecanismo restrictivo del ámbito personal donde han de ser buscados los candidatos a la sucesión regia, ámbito que queda perfectamente delimitado mediante el concepto, más restringido que amplio, de Familia Real, del que existe, además, una expresa concreción en el artículo 2 del Real Decreto 2917/1981, de 27 de noviembre, sobre Registro Civil de la Familia Real, cuando se refiere "al Rey de España, su Augusta Consorte, sus ascendientes, sus descendientes y al Príncipe heredero de la Corona». De esta relación, es claro que no se hallan incluidos en el orden sucesorio, por aplicación del principio de primogenitura, ni el Rey o Reina consorte, ni los ascendientes. El Príncipe heredero aparece relacionado aparte de los descendientes porque, 
en el futuro, podría tener la condición de sucesor, por ejemplo, un sobrino del Rey (si éste no se casara o no tuviera descendencia), lo que es imposible que ocurra con el monarca actual, pues para que un sobrino le sucediera en el trono sería obligado aplicar el principio de consanguinidad partiendo desde uno de sus ascendientes, lo que sería contrario al artículo 57.1 CE, al establecer éste expresamente la dinastía a partir de la persona del Rey D. Juan Carlos I, que se convierte así, como cabeza de tal dinastía, en el único referente a tener en cuenta para determinar las líneas sucesorias. El principio de propincuidad no puede tampoco ser de aplicación, ni siquiera subsidiaria, ya que -según ya se expuso- no es contemplado, ni expresa ni implícitamente, por el citado precepto constitucional cuando fija los criterios configuradores del orden de sucesión a la Corona.

De este modo, si descendemos al campo de lo concreto, los sucesores del Rey D. Juan Carlos I han de ser exclusivamente las personas, actuales y futuras, integrantes de las líneas encabezadas por el Príncipe de Asturias, D. Felipe de Borbón, y de sus hermanas las Infantas $D^{a}$. Elena y $D^{a}$. Cristina, siguiendo este mismo orden. Pero, según nuestro criterio, no hay más líneas sucesorias. En definitiva, pues, el orden de sucesión hoy vigente es el conformado de la manera siguiente: el Príncipe de Asturias, la Infanta Elena, los dos hijos de ésta, la Infanta Cristina y sus tres hijos. Y se trata de una relación exhaustiva, sólo ampliable a los futuros descendientes de las tres cabezas de línea (el Príncipe heredero y las dos Infantas).

\subsection{Los hijos adoptivos en el orden de sucesión}

Dada la igualdad en el orden civil de los distintos tipos de filiación, surge de forma inevitable la pregunta acerca de si un hijo adoptivo del Rey puede aspirar a sucederle en la Corona en igualdad con el resto de los hijos biológicos, si los hubiere. Lo primero que debe quedar claro es que la aplicación de las normas civiles al campo de lo público no puede regirse por un simple automatismo, ya que se trata de un terreno - el de la organización del Estado y, además, en su nivel más alto- donde todas las prevenciones son pocas y al que, por tanto, no cabe trasladar sin más todas las disposiciones del orden civil, sino sólo aquéllas que sean compatibles con los principios que deben regir en el ámbito público.

Hecha esta precisión previa, lo cierto es que la respuesta a la pregunta planteada, que -en nuestra opinión- debe ser la negativa, cabe 
fundamentarla sobre sus propios argumentos jurídicos. El primero de ellos es que el principio de primogenitura, rector del orden sucesorio y al que hace mención expresa - según ya se ha visto-el artículo 57.1 $\mathrm{CE}$, lleva implícito el de consanguinidad, toda vez que, como afirma TORRES DEL MORAL, «evoca derecha y hasta etimológicamente la procreación en el seno de la Familia regia» ${ }^{128}$. Este primer argumento parece ratificarlo el artículo $57.2 \mathrm{CE}$ cuando se refiere a la adquisición de la condición de Príncipe heredero «desde su nacimiento». Y existe todavía un tercer argumento: si se admite la posibilidad de que un hijo adoptivo suceda al Rey, puede eludirse en la práctica el precepto constitucional que dispone, ante la inefectividad en la aplicación del principio hereditario, la designación por las Cortes del nuevo Rey. En otras palabras, el Rey sin descendientes naturales podría, mediante el ejercicio de la adopción, asumir el papel reservado a las Cortes por el artículo 57.3 CE de proveer a la sucesión en la Corona. Así pues, para evitar este riesgo de fraude constitucional debe rechazarse la posibilidad planteada ${ }^{129}$.

\subsection{La aplicación del principio electivo, ¿causa de mutación constitucional?}

Algún sector doctrinal ha querido ver en la elección del Rey por las Cortes, si se han extinguido las líneas llamadas en Derecho, una transformación de la Monarquía hereditaria, consagrada en la Constitución, en una Monarquía electiva. Así, en opinión de FERNÁNDEZFONTECHA y PÉREZ DE ARMIÑÁN, en el caso de que hubiere de aplicarse el artículo 57.3 CE sólo cabe una doble opción: o las Cortes se sujetan a la "dinastía histórica" mencionada en el artículo $57.1 \mathrm{CE}$, designando al Rey de entre miembros de dicha dinastía, por aplicación del principio de propincuidad ${ }^{130}$; o, de no ser así, "se daría un fenó-

128 Torres del Moral, El Príncipe..., op. cit., pág. 73.

129 En parecidos términos, TORRES DEL MORAL, para quien el artículo 57.3 «no permite la introducción de una vía sucesoria no constitucional en detrimento de una función de las Cortes tan importante como la indicada y expresamente conferida por nuestra norma suprema". Este argumento le lleva a la conclusión de que "el ordenamiento constitucional español no acoge la institución de la adopción en la Real Familia", conclusión que no compartimos, ya que, en nuestra opinión, una cosa es la posibilidad de adopción y otra muy distinta que el adoptado adquiera la condición de sucesor regio. Vid. TORRES DEL MORAL, El Príncipe..., op. cit., pág. 74.

130 En este sentido, los autores mencionados defienden la idea de que "la Monarquía en la Constitución está configurada de una forma determinada y que, 
meno de tránsito de la Monarquía hereditaria a la Monarquía electiva en virtud de un acto singular realizado por las Cortes, cuya naturaleza es de difícil catalogación y, por lo tanto, la total subversión del orden jurídico establecido en torno a la Corona en el sistema constitucional español’ ${ }^{131}$. En parecidos términos se expresa también SÁlZ ARNÁlZ, para quien "la decisión parlamentaria ha de entenderse condicionada por la pertenencia del titular a la "dinastía histórica" aludida en el artículo 57.1 CE. [...] En fin, el vínculo a la dinastía histórica evita que las Cortes, decidiendo al margen de aquélla siempre que no pueda considerarse extinguida, provoquen una auténtica mutación constitucional por la vía del acuerdo que han de adoptar a tenor del artículo 57.3 CE"132. Resulta, a nuestro parecer, sorprendente el énfasis que los autores citados ponen en el presumible papel que constitucionalmente debe jugar la denominada "dinastía histórica" cuando, en el uso habitual del idioma español, calificar algo de "histórico" viene a significar, precisamente, que pertenece al pasado $y$, por tanto, que no tiene vigencia actual ni, mucho menos, proyección hacia el futuro. Esta normal acepción del adjetivo "histórica» es la que creemos que adopta el artículo 57.1 CE al calificar así a la dinastía de la que considera al Rey D. Juan Carlos "legítimo heredero", limitándose, por tanto, a describir una cualidad del monarca que es históricamente cierta, pero que no constituye, en ningún caso, la base causal del otorgamiento a su persona del título regio. Otra cosa hubiera sido que la calificara de "legítima", en lugar de "histórica". De esta forma, lo que nuestra Constitución quiere significar es, precisamente, la contraposición entre una dinastía "histórica", que considera perteneciente al pasado, y una nueva dinastía nacida ope Constitutionis y proyectada al futuro, cuyo fundador -el Rey D. Juan Carlos I- viene a constituir, como "legítimo heredero de la dinastía histórican, el punto de engarce con esa dinastía, a la que, por supuesto, no se le puede asignar ningún papel constitucional, en tanto que no tiene ninguna vigencia actual. Éste y no otro es el sentido del inciso del artículo 57.1 CE, a que venimos haciendo referencia.

a estos efectos, el carácter hereditario de la misma, fundado en una dinastía que se califica por la Constitución de histórica, impide a las Cortes el realizar una elección que no sea congruente con los propios principios de la misma. Desde este punto de vista, sí que estaríamos dispuestos a aceptar ese principio de propincuidad, como aproximativo a una solución a lo que es una auténtica laguna constitucional en potencia». Cfr. Fernández-FonteCha y PÉrez de Armiñán, La Monarquía..., op. cit., pág. 207.

Fernández-Fontecha y Pérez de Armiñan, La Monarquía..., op. cit., pág. 205.

132

SÁlz ARnÁlz, "La sucesión...", op. cit., págs. 428-429. 
No estamos de acuerdo tampoco con el riesgo de mutación constitucional en caso de elección parlamentaria del Rey. Por el hecho de que esto ocurra no puede desencadenarse una transformación del carácter hereditario de la Monarquía previsto en la Constitución, ya que, una vez designado por las Cortes el nuevo monarca, la sucesión futura de éste seguirá rigiéndose por el principio hereditario y los demás principios rectores, a los que ya hemos hecho referencia. $Y$ esto es así porque el artículo 57.1 CE no dice que la Corona española sea hereditaria en los "descendientes" del actual monarca, lo que hubiera obligado, en caso de elección parlamentaria de un rey, a reformar el texto de dicho artículo para sustituir la mención a $\mathrm{D}$. Juan Carlos por el nombre del nuevo rey, con el riesgo de que, si no se llegaran a cumplir los requisitos exigidos para tal reforma, la Monarquía se transformara, efectivamente, en electiva. Por el contrario, el término utilizado es el de "sucesores", que es más amplio que el de "descendientes" y que debe ser interpretado en el sentido de que incluye no sólo a los descendientes del Rey actual por vía de filiación natural y legítima, sino también a las personas que, no teniendo esta condición, le sucedan por la vía subsidiaria de la elección parlamentaria. De esta forma, el Rey que designen discrecionalmente las Cortes, cuando se extingan "todas las líneas llamadas en Derecho", será un "sucesor" más de D. Juan Carlos $y$, por tanto, no hará falta ninguna reforma del texto constitucional para que la Monarquía conserve el carácter hereditario consagrado en el mismo. De ahí que, desde la óptica del constituyente de 1978 , el supuesto de extinción ${ }^{133}$ de las líneas sucesorias directas (es decir, de las tres únicas posibles, por vía de filiación natural y matrimonial, a partir del actual monarca) no tenga por qué implicar necesariamente la extinción del título, como sostiene LÓPEZ VILAS ${ }^{134}$, sino

133 Entendemos este término, siguiendo a SÁlZ ARNÁlZ, en el sentido de imposibilidad de identificar al sucesor conforme a los criterios establecidos en el artículo 57.1 CE. No compartimos con este autor, sin embargo, que de este artículo no puedan quedar definidas cuáles sean las líneas sucesorias del Rey D. Juan Carlos (que, como hemos dicho, sólo son tres). Vid. SÁlz ARNÁlz, "La sucesión...", op. cit., págs. $422-423$.

134 Según este autor, como el principio de propincuidad opera hasta el,infinito, aunque siempre dentro de la consanguinidad, si todas las líneas se han extinguido es que el título también se ha extinguido, es decir, ha incidido en caducidad. De ahí -sigue diciendo- que sea "una inexactitud técnica hablar de extinción de línea. Sin línea no se puede medir el grado, dada la supeditación de éste a aquélla. Porque si los que se extinguen son los miembros de una línea, ésta permanece y hace posible la aplicación del grado. El grado no es concebible sino dentro y en consideración a la línea o líneas". Vid. LóPEZ VILAS, "La sucesión...", op. cit., pág. 143. 
que, por el contrario, a lo que debe dar lugar es a una sucesión en él por parte de la persona designada por las Cortes, sin alteración de ninguna característica propia de la Monarquía constitucionalmente prevista. En definitiva, la sucesión de ese hipotético rey electo se verificará, sin necesidad de ninguna reforma constitucional, aplicando los mismos principios rectores que ya han sido estudiados $y$, entre ellos, desde luego y en primer lugar, el principio hereditario.

Una vez solucionados los tres problemas teóricos planteados en torno al orden sucesorio constitucionalmente previsto, procede ya cerrar, al menos de momento, lo que ha querido ser un sereno proceso de reflexión sobre uno de los aspectos más relevantes de la institución monárquica, al que nuestra norma suprema de 1978 quizás no ha dedicado toda la atención que, sin duda, merece. Debemos terminar, pues, este trabajo haciendo un respetuoso llamamiento al Legislativo para que, en uso de sus competencias constitucionales, proceda a realizar, tras su oportuno estudio y debate, una fecunda labor de desarrollo de las previsiones constitucionales sobre el régimen de sucesión a la Corona española, de tal manera que llegue a ser mínima esa posibilidad, hoy tan cierta, de que aparezcan situaciones juridicamente conflictivas en materia de abdicaciones y renuncias o de que surjan dudas de derecho en relación con el orden sucesorio. Como parece obvio, las dudas de hecho son, por hipótesis y, si se quiere, también por desgracia, absolutamente inevitables. 